\title{
Ultrastructural evidence of microglial heterogeneity in Alzheimer's disease amyloid pathology
}

\author{
Hassan El Hajj ${ }^{1 \dagger}$, Julie C. Savage ${ }^{1 \dagger}$, Kanchan Bisht ${ }^{1}$, Martin Parent ${ }^{2,3}$, Luc Vallières ${ }^{1,4}$, Serge Rivest ${ }^{1,4}$ and \\ Marie-Ève Tremblay ${ }^{1,4^{*}}$
}

\begin{abstract}
Background: Alzheimer's disease (AD) is the most common neurodegenerative disease, characterized by the deposition of extracellular fibrillar amyloid $\beta$ (fA $\beta$ ) and the intracellular accumulation of neurofibrillary tangles. As $A D$ progresses, $A \beta$ drives a robust and prolonged inflammatory response via its recognition by microglia, the brain's immune cells. Microglial reactivity to $f A \beta$ plaques may impair their normal surveillance duties, facilitating synaptic loss and neuronal death, as well as cognitive decline in AD.

Methods: In the current study, we performed correlative light, transmission, and scanning electron microscopy to provide insights into microglial structural and functional heterogeneity. We analyzed microglial cell bodies and processes in areas containing $f A \beta$ plaques and neuronal dystrophy, dystrophy only, or appearing healthy, among the hippocampus CA1 of 14-month-old APP ${ }^{\text {Swe }}$-PS1 1 e9 mice versus wild-type littermates.
\end{abstract}

Results: Our quantitative analysis revealed that microglial cell bodies in the AD model mice were larger and displayed ultrastructural signs of cellular stress, especially nearby plaques. Microglial cell bodies and processes were overall less phagocytic in AD model mice. However, they contained increased fibrillar materials and non-empty inclusions proximal to plaques. Microglial cell bodies and processes in AD model mice also displayed reduced association with extracellular space pockets that contained debris. In addition, microglial processes in healthy subregions of AD model mice encircled synaptic elements more often compared with plaque-associated processes. These observations in mice were qualitatively replicated in post-mortem hippocampal samples from two patients with AD (Braak stage 5).

Conclusion: Together, our findings identify at the ultrastructural level distinct microglial transformations common to mouse and human in association with amyloid pathology.

Keywords: Microglia, Alzheimer's disease, Mouse model, Ultrastructure, Electron microscopy

\section{Introduction}

Alzheimer's disease (AD) is the most common neurodegenerative disease, affecting 47 million people in a demographically aging world [1]. The disease causes deficits in memory, learning, and thinking abilities [2]. The best neuropathological correlates of cognitive decline in $\mathrm{AD}$ are neuronal dystrophy and synaptic loss, which are

\footnotetext{
* Correspondence: tremblay.marie-eve@crchudequebec.ulaval.ca Hassan El Hajj and Julie C. Savage have equal contribution as co-first authors 'Axe neurosciences, Centre de recherche du CHU de Québec-Université Laval, 2705, boulevard Laurier, T2-50, Quebec, QC G1V 4G2, Canada ${ }^{4}$ Département de médecine moléculaire, Faculté de médecine, Université Laval, Quebec, QC, Canada

Full list of author information is available at the end of the article
}

associated with increased network excitability, notably of the hippocampus, and precede neuronal death $[3,4]$. While the hippocampus is pivotal for long-term memory formation in addition to its essential role in memory storage and retrieval [5], hippocampal atrophy is consistent in AD with a mean volume loss ranging from 20 to $50 \%$ [6]. The main pathological hallmarks of $\mathrm{AD}$ are the deposition of extracellular amyloid beta $(A \beta)$ plaques, comprising insoluble $A \beta$ fibrils (fA $\beta$ ), and intraneuronal fibrillar tangles of tau protein [7]. The soluble amyloid beta $(\mathrm{sA} \beta)$ forms a halo around $f A \beta$ plaques and is linked to neuronal dystrophy and synaptic loss, both in AD human samples and mouse models of $A \beta$ deposition [8-13]. 
Genome-wide association studies (GWAS) have uncovered a strong genetic involvement of the immune system in $\mathrm{AD}$, including functional variants of triggering receptor expressed on myeloid cells 2 (TREM2) [14-16]. Microglia, the resident innate immune cells of the brain, recognize and respond to both $\mathrm{sA} \beta$ and $\mathrm{fA} \beta$ using complexes of pattern recognition receptors [17]. Downstream signaling induces tumor necrosis factor alpha (TNF $\alpha)$ and interleukin-1 beta (IL-1 $\beta$ ) secretion, which recruits nearby microglial cells via chemotaxis and can initiate a runaway inflammatory response that injures neurons as well as triggers synaptic loss [18-21]. In the healthy brain, the complement cascade mediates the pruning of less active synapses, while in aging and $\mathrm{AD}$, this pathway takes a pathological role and promotes synaptic loss [20]. Microglia are firmly connected to brain inflammation and they likely contribute to its harmful long-term consequences leading to neurodegeneration and cognitive decline [9]. Microglia are also instrumental in slowing down the plaque growth and reducing synaptic loss by preventing $A \beta$ diffusion and toxicity $[22,23]$, while they perform valuable roles in the clearance of both $\mathrm{sA} \beta$ and fA $\beta$ [24, 25]. Microglial contribution to $A \beta$ clearance can prevent the precipitation of $A \beta$ into fibrillar plaques and reduce the brain concentration of harmful sA $\beta$ species responsible for neurodegenerative effects; a number of therapeutic studies have thus focused on increasing microglial capacity to clear sA $\beta$ and $\mathrm{fA} \beta$ [26-28]. Additionally, microglia were involved in extracellular degradation of $A \beta$ both in vitro and in vivo $[29,30]$.

Microglial implication in the pathological process of $\mathrm{AD}$ is contextual [31,32] and heterogeneous, as illustrated by recent single cell transcriptomic studies [33]. For instance, the disease-associated microglia (DAM) and microglia neurodegenerative phenotype (MGnD) transcription signatures contain reduced levels of homeostatic genes, higher levels of phagocytic genes, and were shown to associate with $f A \beta$ plaques in $A D$ mouse models and human samples [34-36]. They are also regulated by TREM2 [37]. The functional outcomes of these altered microglial transcriptomes largely remain undetermined, however, and this leaves open the question of whether and how these phenotypes clear $A \beta$ and apoptotic neurons. Using ultrastructural analysis, our group recently described the dark microglia [36], which extensively contact synapses and are characterized by their electron-dense cytoplasm and nucleoplasm in electron microscopy. These cells are rare in the mature brain during normal physiological conditions, but they become abundant in aging and in the $\mathrm{APP}^{\mathrm{Swe}}-\mathrm{PS} 1 \Delta \mathrm{e} 9$ mouse model of amyloid deposition. In this AD model, dark microglia often associated with plaques, expressed TREM2, contained fibrillar materials, and encircled dystrophic neurites and synaptic elements. Interestingly, intermediate stages between the dark and typical microglia were observed, while the typical microglia displayed several ultrastructural alterations in $\mathrm{APP}^{\text {Swe }}$-PS1 $1 \mathrm{e} 9$ mice.

To provide further insights into the implication of microglial diversity in $\mathrm{AD}$, the present study aimed to define the spatial heterogeneity of microglial ultrastructure with relation to $\mathrm{fA} \beta$ plaques, as well as neuronal dystrophy and synaptic loss, using $\mathrm{APP}^{\text {Swe }}$-PS1 $1 \mathrm{e} 9$ mice [38]. This well-established model deposits fA $\beta$ plaques within the cortex and hippocampus beginning at 4 months of age, with cognitive deficits and synaptic loss detected at 6 months, and robust memory deficits by 12 months [37-40]. In the current study, we investigated microglial ultrastructure among subregions of the ventral hippocampus CA1 with $\mathrm{fA} \beta$ plaques and neuronal dystrophy, neuronal dystrophy without plaques, or that appeared unaffected by $\mathrm{A} \beta$ pathology. We used a combination of correlative light, transmission, and scanning electron microscopy [41]. The $\mathrm{APP}^{\mathrm{Swe}}-\mathrm{PS} 1 \Delta \mathrm{e} 9$ mice were compared to wild-type littermate controls at 14 months of age, when sufficient plaque deposition allowed to study all three subregions simultaneously, within the same tissue sections. We focused on the CA1 strata radiatum and lacunosum-moleculare, two layers containing the apical dendrites of CA1 pyramidal cells, where the dark microglia were previously shown to be abundant [36]. In addition, microglial ultrastructure was analyzed in the post-mortem hippocampus of two patients with AD (Braak stage 5). Our observations reveal various microglial changes in response to amyloid pathology, some of which being specific to areas containing fA $\beta$ plaques (e.g., endosomes enclosing elements), to areas showing neuronal dystrophy without fA $\beta$ plaques (e.g., association with extracellular debris), or to areas appearing devoid of pathology (increased contacts with synaptic elements). Together, our overall findings suggest that while microglia undergo global ultrastructural changes over the course of amyloid pathology, the local environment largely determines their diversity.

\section{Methods}

Animals

All experimental procedures were performed in agreement with the guidelines of the Institutional Animal Ethics committees, in conformity with the Canadian Council on Animal Care and the Animal Care Committee of Université Laval. The animals were housed under a 12-h light-dark cycle at $22-25{ }^{\circ} \mathrm{C}$ with free access to food and water. Fourteen-month-old $\mathrm{APP}^{\text {Swe }}$-PS1 $1 \mathrm{e} 9$ mice on a $\mathrm{C} 57 \mathrm{Bl} / 6 \mathrm{~J}$ background $(N=4)$ were compared with age-matched wild-type littermate controls $(N=3)$. The transgenic mice coexpress human presenilin one variant (A246E) and a chimeric mouse/human amyloid precursor protein (APPSwe) [37]. Only males were used 
in this study considering sex differences in amyloid deposition that were described in $\mathrm{APP}^{\mathrm{Swe}}$-PS1 $\Delta \mathrm{e} 9$ mice [42].

$\mathrm{APP}^{\mathrm{Swe}}$-PS1 $\triangle \mathrm{e} 9$ mice were injected with Methoxy-X04 (10 g/kg; Tocris Bioscience) $24 \mathrm{~h}$ prior to sacrifice as previously described [41]. Methoxy-X04 is a Congo Red fluorescent derivative that binds to $\beta$ sheets with high affinity. Mice were anesthetized with sodium pentobarbital (80 $\mathrm{mg} / \mathrm{kg}$, i.p.) and transcardially perfused with ice-cold phosphate-buffered saline (PBS; $50 \mathrm{mM}$ at $\mathrm{pH}$ 7.4) followed by $3.5 \%$ acrolein and $4 \%$ paraformaldehyde both diluted in phosphate buffer (PB; $100 \mathrm{mM}$ at $\mathrm{pH} 7.4$ ). Transverse sections of the brain (50- $\mu \mathrm{m}$-thick) were cut in PBS using a vibratome (Leica VT1000S) and kept in a cryoprotectant solution containing glycerol and ethylene glycol at $-20{ }^{\circ} \mathrm{C}$ until further processing $[41,43]$.

\section{Screening brain sections for $f A \beta$ plaques using light microscopy}

With the aid of a stereotaxic mouse brain atlas [44], brain sections containing the ventral hippocampus CA1 (Bregma -2.75 to -3.5 ) were selected and placed into a 24-well plate. Each section was assigned an individual well. Using an ultraviolet filter with a range of 380-480 nm, an inverted Nikon Eclipse TE300 microscope was used to visualize the methoxy-X04 stained plaques at a magnification of $\times 4$. Pictures of the sections were captured both in bright and fluorescent field modes, naming the images according to the sections position into the 24-well plate [41]. Brain sections from the age-matched controls containing the same level of ventral hippocampus as the Methoxy-X04-labeled sections were selected for comparison.

\section{Human tissue}

Hippocampal sections containing the CA1 from two human cases of $\mathrm{AD}(\mathrm{C}-0032,76$ years of age, 24-h postmortem delay; $\mathrm{H}-17,81$ years of age, 6-h post-mortem delay) were obtained from the brain bank established at the CERVO Brain Research Center. The two samples are considered typical cases of $\mathrm{AD}$ with similar levels of pathology, staged 5 out of 6 on the Braak scale. In the two samples, Bielschowsky staining revealed moderate numbers of $\mathrm{fA} \beta$ plaques, especially in the parietal and temporal lobes. With regard to the hippocampus, an overall atrophy was noted, together with a moderate number of $f A \beta$ plaques. Brain banking and post-mortem tissue handling procedures were approved by the Ethic Committee of the Institut Universitaire en santé mentale de Québec and by Université Laval. Brains were obtained with written consent and the analyses performed in conformity with the Code of Ethics of the World Medical Association (Declaration of Helsinki). Brains were first cut in half along the midline and hemibrains were sliced into 2-cm-thick slabs along the coronal plane. These slabs were fixed by immersion in $4 \%$ paraformaldehyde at $4{ }^{\circ} \mathrm{C}$ for 3 days. They were stored at $4{ }^{\circ} \mathrm{C}$ in $\mathrm{PBS}(100 \mathrm{mM}$ at pH 7.4) containing $15 \%$ sucrose and $0.1 \%$ sodium azide. Slabs containing the hippocampus CA1 were cut with a freezing microtome into $50-\mu \mathrm{m}$-thick sections that were serially collected in PBS and stored at $-20{ }^{\circ} \mathrm{C}$ in a cryoprotectant solution containing glycerol and ethylene glycol until use.

\section{Brain sections immunostaining and processing for electron microscopy}

Hippocampal sections from the human cases, wild-type littermate controls, and $\mathrm{APP}^{\mathrm{Swe}}$ - $\mathrm{PS} 1 \Delta \mathrm{e} 9$ mice containing $\mathrm{A} \beta$ plaques in the CA1 were selected for immunohistochemical (immuno)EM staining. They were washed in PBS, quenched with $0.3 \%$ hydrogen peroxide $\left(\mathrm{H}_{2} \mathrm{O}_{2}\right)$ in $\mathrm{PBS}$, and washed again. Sections were then incubated with $0.1 \%$ solution of $\mathrm{NaBH}_{4}$ for $30 \mathrm{~min}$ at room temperature (RT). After several washes, sections were incubated in a blocking buffer of Tris-buffered saline (TBS; $50 \mathrm{mM}$ at $\mathrm{pH} 8.0$ ) containing $10 \%$ fetal bovine serum, 3\% bovine serum albumin, and $0.01 \%$ Triton $\mathrm{X} 100$ for $2 \mathrm{~h}$ at RT. Sections were incubated overnight at $4{ }^{\circ} \mathrm{C}$ in rabbit anti-ionized calcium binding adaptor molecule 1 (IBA1) antibody (1:1000 in blocking solution; Wako Pure Chemical Industries) and rinsed in TBS. The sections were afterwards incubated for $1.5 \mathrm{~h}$ in goat anti-rabbit IgGs conjugated to biotin (1:200 in TBS; Jackson Immunoresearch) and $1 \mathrm{~h}$ in the ABC Vectastain system kit (1:100 in TBS; Vector Laboratories) for immunoperoxidase staining. The staining was revealed using diaminobenzidine (DAB; $0.05 \%$ ) and $\mathrm{H}_{2} \mathrm{O}_{2}$ $(0.015 \%)$ in TBS for $8 \mathrm{~min}$. Sections were post-fixed flat in $1 \%$ osmium tetroxide in $\mathrm{PB}$ for $30 \mathrm{~min}$ and dehydrated in increasing concentrations of ethanol, immersed in propylene oxide, impregnated in Durcupan resin (Electron Microscopy Sciences; EMS) overnight at RT, and polymerized between ACLAR films (EMS) at $55{ }^{\circ} \mathrm{C}$ for $72 \mathrm{~h}$. Areas of interest were excised from the embedded sections, glued to resin blocks [41], and sectioned at 70-80 nm using a Leica UC7 ultramicrotome.

\section{Transmission electron microscopy imaging}

Ultrathin sections collected on square mesh grids (EMS) were imaged using a FEI Tecnai Spirit G2 microscope equipped with an ORCA-HR Hamamatsu (10MP) camera. Microglial cell bodies were identified using a series of distinctive features that comprise their electron density, association with extracellular space pockets, characteristic long stretches of endoplasmic reticulum (ER), numerous vacuoles and intracellular inclusions, irregular contours with obtuse angles, and small elongated nucleus delineated by narrow nuclear cisternae [45, 46]. In most cases, they were also identified by their IBA 1 immunoreactivity. Our analysis did not distinguish between the 
yolk-sac derived microglia and circulating myeloid cells that infiltrate the brain [47].

For qualitative analysis, pictures were acquired at magnifications ranging from $\times 1400$ to $\times 13,000$. Both mouse and human hippocampal samples were analyzed qualitatively to investigate microglial interactions with the synaptic neuropil, including contacts with dystrophic neurites and dendritic spines, phagocytosis, and association with extracellular space pockets containing debris. For quantitative analysis in the mouse samples, pictures of microglial cell bodies and processes were randomly acquired, at $\times 6800$ and $\times 9300$, respectively. In the $\mathrm{APP}^{\text {Swe }}$-PS1 $\triangle \mathrm{e} 9$ mice, three different subregions were differentiated. The first subregion contained one $f A \beta$ plaque, with some rare cases showing two fA $\beta$ plaques, accompanied by neuronal dystrophy within a $113 \mu \mathrm{m} \times$ $113 \mu \mathrm{m}$ grid square; the second subregion displayed neuronal dystrophy notably observed as clusters of swelled neurites containing autophagic vacuoles as well as electron dense bodies but no $\mathrm{fA} \beta$ plaque within a $113 \mu \mathrm{m} \times 113 \mu \mathrm{m}$ grid square; and the third subregion only comprised ultrastructurally unaffected neuronal and glial cell compartments with intact plasma membranes and organelles, comparable to the wild-type control samples, within a $113 \mu \mathrm{m} \times 113 \mu \mathrm{m}$ grid square. In the third subregion, myelinated axons were also surrounded by compact sheaths of myelin without ultrastructural alteration. While great care was taken in defining these three subregions in our samples, and the plaques were identified in light microscopy prior to ultrathin sectioning, it is possible that neuronal dystrophy was present outside of the imaged section. The same number of microglial cell bodies and processes was imaged in the wild-type controls, ranging from 7-15 microglial cell bodies and 50-70 microglial processes per subregion/animal. To ensure that some of the larger microglial processes were not, in fact, proximal processes containing part of the soma, a $2 \mu \mathrm{m}^{2}$ area was instituted as an upper bound for microglial process size.

\section{Scanning electron microscopy array tomography imaging}

In order to image microglia near $f A \beta$ plaques in the human tissue, scanning electron microscopy (SEM) with array tomography was used. The same tissue was used for both transmission electron microscopy (TEM) and SEM imaging. However, after ultrathin sections were made, they were collected onto polished silicon chips and treated with $2 \%$ osmium tetroxide in $1.5 \%$ potassium ferrocyanide solution, followed by $1 \%$ thiocarbohydrazide, and $1 \%$ osmium, as described in the National Center for Microscopy and Imaging Research serial blockface SEM protocol [48]. Following this post-fixation, the chips were mounted onto pin stubs using double-sided conductive carbon tape and imaged in a Zeiss Crossbeam 540 SEM, using acceleration voltage of $1.4 \mathrm{kV}$ and current of $1.2 \mathrm{nA}$, at a maximum magnification of $5 \mathrm{~nm}$ per pixel.

\section{Quantitative ultrastructural analysis of microglia}

The analysis of microglial cell bodies and processes comprised several ultrastructural measures of morphology, phagocytic activity, cellular stress, and physiological function. Experimenters were blinded to the experimental conditions throughout the analysis. Size and shape descriptors were determined using ImageJ. For each microglial cell body and process, phagocytic inclusions (appearing electron-lucent and named "empty" versus containing materials and named "non-empty"), lysosomes (primary, secondary, versus tertiary), lipid bodies, fibrillar materials, ER dilation, vacuoles (diameter $<100 \mathrm{~nm}$ ), and extracellular space pockets containing debris were counted, according to the quantitative code $0,1,2$, and $3+$ (designating 3 and more occurrences). Lysosomes were identified by their dense, heterogeneous contents enclosed by a single membrane [49]. Primary lysosomes possessed a homogenous granular content and their diameter ranged from 0.3 to $0.5 \mu \mathrm{m}$ [50]. Secondary lysosomes were 1 to $2 \mu \mathrm{m}$ across, and their content was heterogeneous showing fusion with vacuoles. Tertiary lysosomes ranged in diameter between 1.5 and $2.5 \mu \mathrm{m}$, and they were usually fused to one or two vacuoles associated with lipofuscin granules, as well as lipidic inclusions showing signs of degradation [51]. Lipidic inclusions were identified as the clustering of round organelles with an electron dense, either opaque or limpid, cytoplasm enclosed by a single membrane. Lipofuscin granules were identified by their oval or round shapes, finely granular composition, and associated amorphous materials [51]. Extracellular fA $\beta$ was identified as densely packed fibrils and filaments, according to previous ultrastructural descriptions [52]. ER dilation was recognized by a swelling of the cisternal space ranging from 50 to $300 \mathrm{~nm}$ [53]. Extracellular space pockets containing debris, which could result from "exophagy" (degradation of cellular constituents by lysosomal enzymes released extracellularly), exocytosis (the process of expelling the contents of a membrane-bound vesicle into the extracellular space, often lysosomal and in preparation for phagocytosis; [54]), or pinocytosis (also named bulk-phase endocytosis, by which cells can take up extracellular contents in a non-phagocytic manner; [55]) was defined by the appearance of degraded materials (including cellular membranes and organelles) or debris in the extracellular space juxtaposing the microglia [54].

For microglial processes, their encirclement of neuropil compartments (axon terminals, dendritic spines, synapses between axon terminals and dendritic spines, cellular elements with signs of degradation) was also quantified. Encirclement was defined as microglial interactions with 
these neuropil compartments that displayed at least two points of contact, sometimes extending over several hundreds of nanometers. They were scored using the quantitative code $0,1,2$, and $3+$ (designating 3 and more elements). The encircled elements were identified according to the following criteria: axon terminals contained synaptic vesicles and were frequently seen branching from axons or making synapses onto dendritic branches and spines, and dendritic spines were identified as extensions from dendrites often forming synapses where a postsynaptic density was observed. Moreover, microglial encirclement of extracellular debris was determined.

\section{Statistical analysis}

GraphPad Prism 7 was used for statistical analysis. The $\mathrm{APP}^{\mathrm{Swe}}$-PS1 $\triangle \mathrm{e} 9$ mice were compared to age-matched wild-type littermate controls using a non-parametric Mann-Whitney test. Microglial cell bodies and processes were further compared between plaque-associated, neuronal dystrophy associated, and ultrastructurally healthy tissue of $\mathrm{APP}^{\mathrm{Swe}}$-PS1 $1 \mathrm{e} 9$ mice using a non-parametric Kruskal-Wallis test without matching, followed by Dunn's multiple comparisons post-hoc test. Data are expressed as mean \pm standard error of the mean (SEM) $[56,57]$. The sample size $(n)$ refers to individual microglial cell bodies or processes as previously performed for quantitative ultrastructural analyses [56, 58-60]. Statistically significant differences are indicated by $*, \sim, \# p<0.05$, $* *, \sim \sim, \# p<0.01$, and ${ }^{* * * *}, \sim \sim, \# \# p<0.001$.

\section{Results}

\section{Microglial ultrastructure is altered in proximity to $f A \beta$}

We characterized at nano-scale resolution microglial ultrastructure among subregions containing $f A \beta$ plaques, displaying neuronal dystrophy, or appearing healthy, among the hippocampus CA1 strata radiatum and lacunosum-moleculare of 14-month-old $\mathrm{APP}^{\mathrm{Swe}}-\mathrm{PS} 1 \Delta \mathrm{e} 9$ mice versus wild-type littermates (Fig. 1). Microglial cell bodies displayed, in all four conditions, characteristic bean-shaped nuclei containing patches of dense heterochromatin, while their cytoplasm showed variable levels of immunoEM reactivity against the marker IBA1 (Fig. 1a-d). In line with previous descriptions of microglial ultrastructure [46], their cell bodies contained numerous mitochondria often in close apposition to characteristically long stretches of ER, together with occasional Golgi apparati and phagocytic vesicles (Figs. 1d, $2 \mathrm{a}-\mathrm{c}, 3 \mathrm{a}, \mathrm{b}, 4 \mathrm{a}-\mathrm{c}$, and $5 \mathrm{a}, \mathrm{c})$. When studying whole-region changes in microglial ultrastructure, cell body area was significantly different between wild-type and transgenic mice, showing increase in $\mathrm{APP}^{\mathrm{Swe}}-\mathrm{PS} 1 \Delta \mathrm{e} 9$ animals (Fig. 2d, Table 1). Similar findings were obtained by separating the $\mathrm{APP}^{\mathrm{Swe}}-\mathrm{PS} 1 \Delta \mathrm{e} 9$ investigation into subregions (ultrastructurally healthy, dystrophic, and plaqueassociated with dystrophy) (Fig. 2e, Table 2).

Microglial cell bodies of wild-type and $\mathrm{APP}^{\mathrm{Swe}}-\mathrm{PS} 1 \Delta \mathrm{e} 9$ mice were significantly different in size, but their morphology remained largely unchanged (Table 3 ). Numerous in vivo two-photon imaging studies revealed that microglial processes are incredibly dynamic as they survey the brain neuropil via continuous extension and retraction [61]. Microglial processes are long, thin, often ramified, discontinuous from cell bodies in ultrathin sections, and are identified by their immunoEM staining for IBA1, which diffuses throughout their cytosol (Figs. 2c, 3c-e, 4h-j, and $5 \mathrm{~b}, \mathrm{~d})$. They often accumulate phagocytic vesicles, and more proximal processes also contain mitochondria, occasional ER and/or Golgi apparati, as well as lysosomes. While the area of microglial processes did not differ between genotypes (Table 3), processes from $\mathrm{APP}^{\text {Swe }}$-PS1 $\triangle \mathrm{e} 9$ mice had significantly rounder and more solid shape descriptors (Fig. 2f, g and Table 3).

Although their gross ultrastructural features were not significantly different between wild-type and $\mathrm{APP}^{\mathrm{Swe}}$-PS1 $\Delta \mathrm{e} 9$ mice, microglial cell bodies and processes interacted differently with their surrounding neuropil depending on the genotype. Strikingly, microglial cell bodies and processes in $\mathrm{APP}^{\mathrm{Swe}}$-PS1 $1 \mathrm{e} 9$ mice reduced their association with extracellular space pockets containing debris (Fig. 3a, b, g, i). This debris contained cellular membranes that sometimes formed vesicles (see Figs. 3b, c and 4a). In the healthy adolescent brain, pockets of extracellular space are tightly associated with microglial cell bodies and processes, without noticeable accumulation of materials [45]. Whether this accumulation of debris observed here is associated with exophagy, exocytosis, or macropinocytosis events $[54,55,62]$ warrants further investigation. In addition, differences were observed based on microglial cell body location among subregions of fA $\beta$ plaques, neuronal dystrophy, or apparent health (Fig. 3h). Microglial processes in $\mathrm{APP}^{\mathrm{Swe}}$-PS1 $1 \mathrm{e} 9$ mice similarly reduced their association with extracellular debris (Fig. 3c, i, Table 3). Microglial processes in $\mathrm{APP}^{\mathrm{Swe}}{ }_{\mathrm{PS} 1 \triangle \mathrm{e} 9}$ animals nevertheless encircled more dendritic spines and axon terminals than processes in wild-type animals (Fig. 3e, f, j-m). This increase in encirclement was also noted in conjunction with degraded structures (Fig. 3d), though the trend did not reach statistical significance (Table 3 ). However, in the subregions of $\mathrm{fA} \beta$ plaques, microglial processes were less likely to encircle synaptic elements, while more likely to encircle fibrils of amyloid (Fig. 3m, n). This data indicates that microglia respond to global changes (i.e., increased interactions with synapses in AD model), but still halt normal surveillance duties when in the immediate presence of fA $\beta$. 

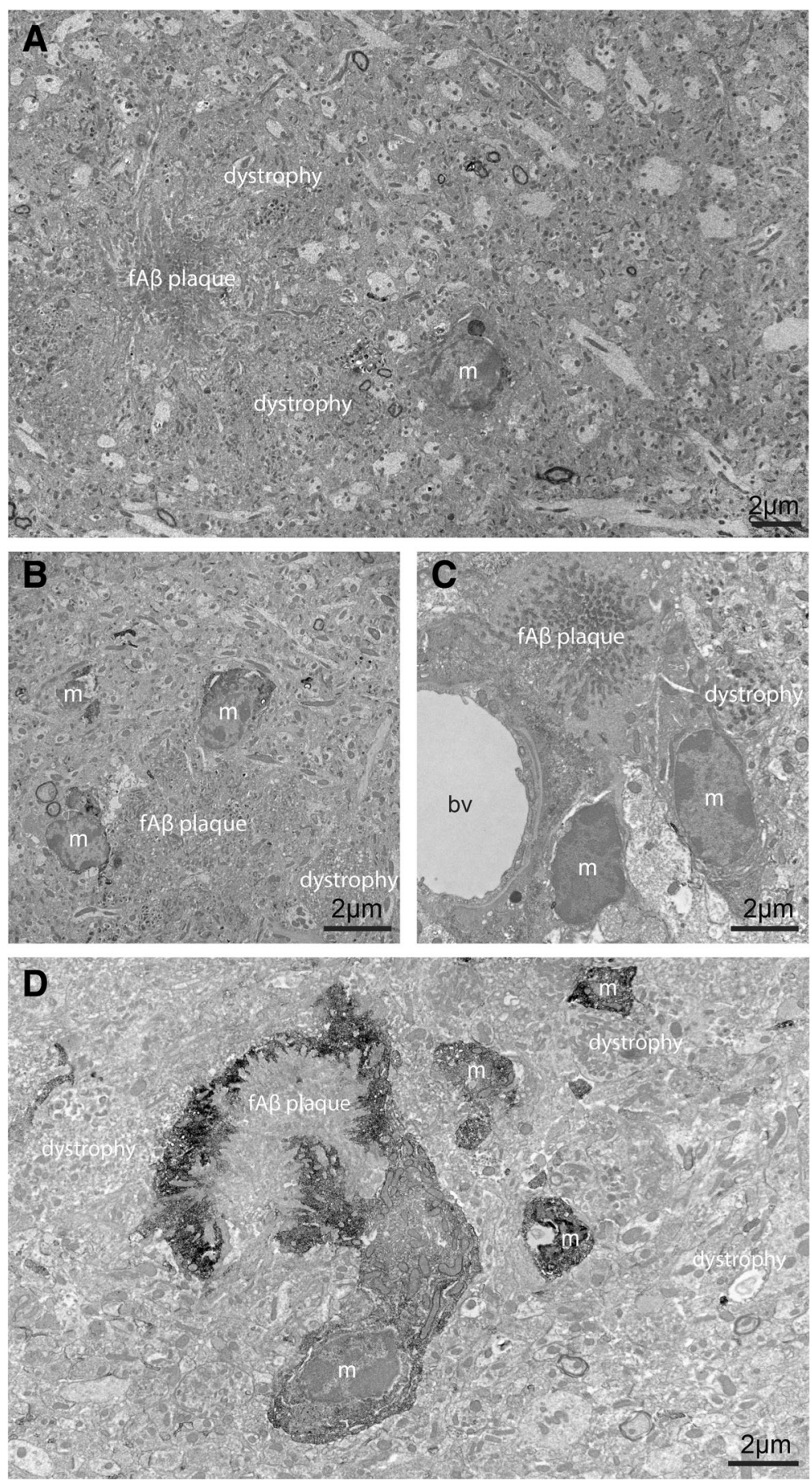

Fig. 1 Defining dystrophic and plaque-associated neuropil areas. a An example EM image displaying a microglial cell body in plaque- and dystrophic-associated region of the ventral hippocampus CA1 in APPSwe $P S 1 \Delta$ e9 model mice. $\mathbf{b}$ Two microglial cell bodies and a microglial process showing IBA1 immunoreactivity surround a $\mathrm{fA} \beta$ plaque and associated dystrophy. $\mathbf{c}$ A microglial cell body contacts both a dystrophic neurite and a fA $\beta$ plaque while a second microglial cell contacts a blood vessel. $\mathbf{d}$ A microglial cell body and its proximal process displaying IBA1 immunoreactivity encircle a fAß plaque. Other microglial processes, discontinuous to the cell body in ultrathin section, can also be seen. bv blood vessel, $m$ microglia. Dystrophy and $f A \beta$ plaques are labeled throughout the figure 

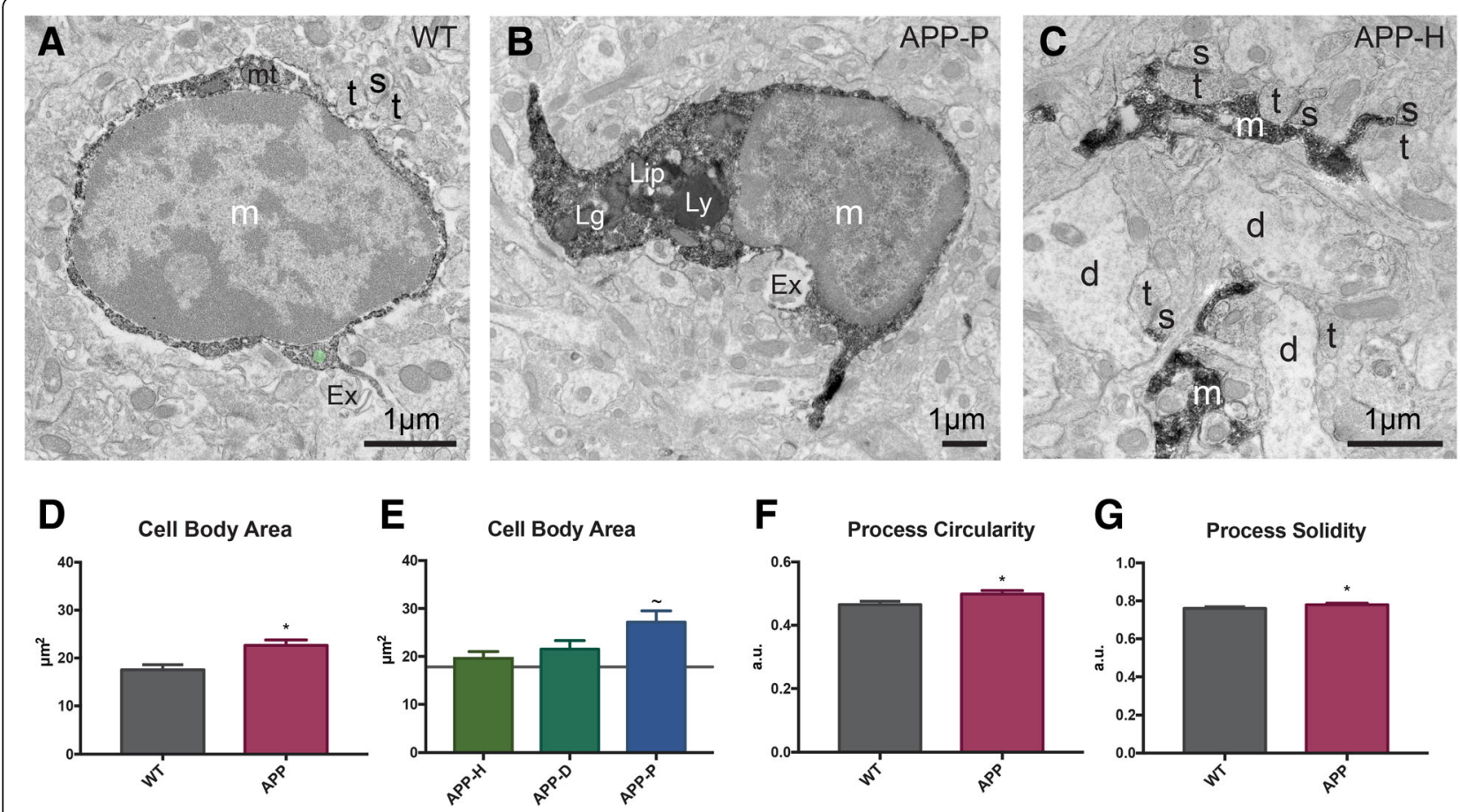

Fig. 2 Microglial ultrastructure is changed by proximity to fAß plaques. a EM image from a WT control animal showing oval shaped IBA1-positive microglial cell body contacting extracellular space pocket and axon terminal in the ventral hippocampus CA1. b EM image of a plaque-associated microglial cell body that contains lipidic inclusions, lipofuscin granule, and lysosome, as well as contacting extracellular space pocket. c Microglial processes in an ultrastructurally healthy subregion of APPSwe - PS1 $1 \mathrm{e} 9$ mouse model, touching or encircling various types of synaptic elements. $d$ dendrite, Ex extracellular space pocket containing debris, $L g$ lipofuscin granule, Lip lipidic inclusion, $L y$ lysosome, $m$ microglia, $m t$ mitochondrion, $s$ dendritic spine, $t$ axon terminal. $\mathbf{d}$ Change in microglial cell body area of WT controls compared to APPSWe_PS1 $\Delta$ e9 animals. e Change in microglial cell body area in APP-H, APP-D, and APP-P subregions. $\mathbf{f}$ Change in the microglial process circularity in WT and APPSwe-PS1 $\triangle$ e9 animals. $\mathbf{g}$ Change in the microglial process solidity in WT and APP ${ }^{\text {Swe }}$-PS1 1 e9 animals. $n=50$ processes per condition for APP-H, APP-D, and APP-P and 70 processes per animal for WT animals, $n=7-15$ cells per condition for all conditions, and data was collected from $N=3-4$ animals per condition. All error bars are mean \pm SEM. WT levels are shown on the subregion graphs by a gray horizontal line. ${ }^{*} p<0.05$ difference from WT, $\sim p<0.05$ difference from APP-H

\section{Microglial phagocytosis is reduced in AD model mice}

One of microglias' most pivotal roles in the development and maintenance of the brain is their capacity to recognize and actively phagocytose, and degrade extraneous synapses and apoptotic cells. Microglia often contain phagocytic inclusions in their cell bodies and processes. Using immunoEM, the cargos contained within the phagocytic vesicles of microglia can be identified (Fig. 4a-c). Microglial cell bodies in $\mathrm{APP}^{\mathrm{Swe}}-\mathrm{PS} 1 \triangle \mathrm{e} 9$ contained fibrillar materials (Fig. 4c, d), only when they were located nearby plaques (Fig. 4f). Empty inclusions appear as electron lucent, while non-empty inclusions are electron dense, and sometimes can be recognized as surrounding membranes, vesicles, or myelin sheaths (Fig. 4a-c). Microglial cell bodies in $\mathrm{APP}^{\text {Swe }}$-PS1 $\triangle \mathrm{e} 9$ mice contained significantly fewer empty inclusions than wild-type animals (Fig. 4e). In contrast, microglial cell bodies located near $f A \beta$ plaques were more likely to contain non-empty inclusions as compared with ultrastructurally healthy subregions (Fig. 4g).

Microglial phagocytosis begins with a microglial membrane wrapping and engulfing its phagocytic target. The vesicle is then trafficked to the soma via the phagolysosomal pathway, undergoing degradation along the way. As expected, the ratio of phagosomes containing nonempty to empty inclusions was higher within microglial processes than microglial somas (Tables 1, 2, 3, and 4). Upon investigation, we found that microglial processes in $\mathrm{APP}^{\mathrm{Swe}}$-PS1 $\triangle \mathrm{e} 9$ mice were not less phagocytic than the processes from wild-type animals (Table 3). However, their total number of inclusions (both empty and non-empty) were significantly reduced in numbers in $\mathrm{APP}^{\mathrm{Swe}}-\mathrm{PS} 1 \Delta \mathrm{e} 9$ mice (Fig. 4k, l). Comparing subregions, fibrillar materials were observed only in processes near plaques (Fig. 4m).

To provide additional insights into the alteration of microglial degradation activity, we next investigated the prevalence and determined the stage of lysosomes in microglial cell bodies and processes (Tables 1, 2, 3, and 4). While primary lysosomes are not commonly found in microglial somas (0.167 per cell body, Table 1$)$, secondary and tertiary lysosomes containing phagocytic or degraded materials were often present in both wild-type 

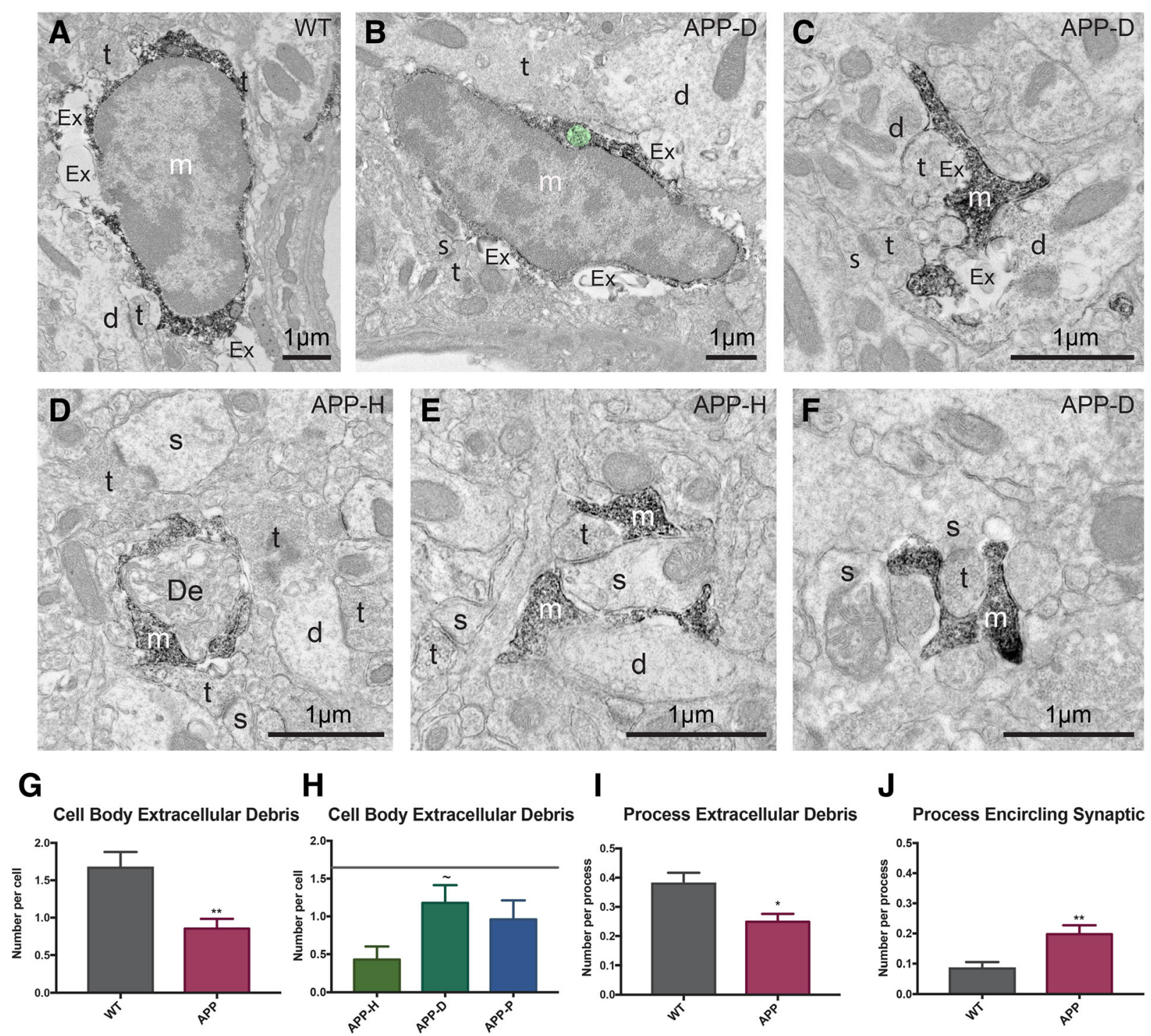

J
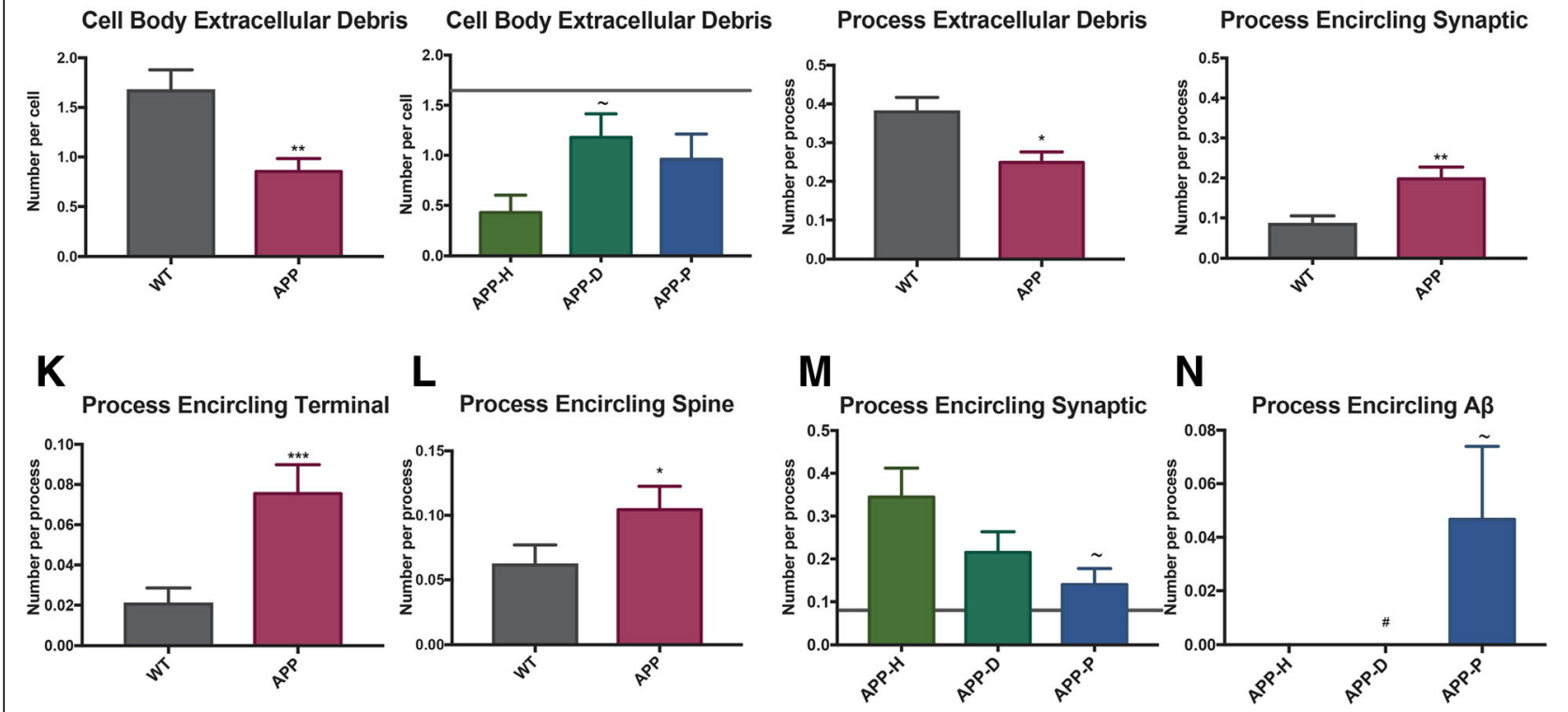

Fig. 3 (See legend on next page.) 
(See figure on previous page.)

Fig. 3 Distinct alterations in microglial interaction with the neuropil, including synaptic structures, in APPSwe_PS1 $\triangle$ e9 animals. a EM image of an IBA1-positive microglial cell body in the ventral hippocampus CA1 of a WT control making numerous contacts with extracellular space pockets containing debris. $\mathbf{b}$ EM image of an IBA1-positive microglial cell body in a section containing dystrophy, making contact with extracellular space pockets and an axon terminal. A non-empty phagocytic inclusion is pseudocolored in green. c An IBA1-positive microglial process makes contacts with extracellular space pockets containing debris, as well as various dendrites and axon terminals. d IBA1-positive microglial process encircling degraded elements in the APP-H subregion. e, $\mathbf{f} \mid \mathrm{BA} 1$-positive microglial processes encircling synapses between axon terminals and dendritic spines in APP-H and APP-D subregions. $d$ dendrite, De degraded element, Ex extracellular space pocket containing debris, $m$ microglia, $s$ dendritic spine, $t$ axon terminal. $\mathbf{g}$ Microglial cell bodies interact less with extracellular debris in APPSwe $-P S 1 \Delta$ e9 mice. $\mathbf{h}$ Microglial cell bodies in APP-H regions interact less with extracellular debris than those in APP-D regions in APP ${ }^{\text {Swe }}$-PS1 1 e9 mice. i Microglial processes in APPSwe_PS1 $\Delta$ e9 mice interact less with extracellular debris than WT processes. $\mathbf{j}-\mathbf{I}$ Processes in APP ${ }^{\text {Swe }}$-PS1 $1 \mathrm{e} 9$ mice encircle more synaptic elements (j) including (k) axon terminals, and (I) dendritic spines. $\mathbf{m}$ Processes in APP-P associated regions encircle fewer synaptic elements than processes in APP-H subregion. $\mathbf{n}$ Only microglial processes in APP-P subregion encircle A $($ mean \pm SEM). WT levels are shown on the subregion graphs by a gray horizontal line. $n=50$ processes per condition for APP-H, APP-D, and APP-P and 70 processes per animal for WT animals, $n=7-15$ cells per condition for all conditions, and data was collected from $N=3-4$ animals per condition. * denotes difference from WT, $\sim$ denotes difference from APP-H, \# denotes difference from APP-P ${ }^{*}, \sim, \# p<0.05$; ${ }^{* *} p<0.01$; ${ }^{* *} p<0.001$

and $\mathrm{APP}^{\mathrm{Swe}}$-PS1 $\triangle \mathrm{e} 9$ animals (between 0.40 and 0.76 per cell body, Table 1). Interestingly, total lysosomes as well as specifically secondary lysosomes increased in microglial processes from plaque-associated areas (Figs. $4 \mathrm{n}$, $5 \mathrm{~d}$, Table 4). Although the number of fibrillar materials inclusions was elevated in the $\mathrm{APP}^{\mathrm{Swe}}-\mathrm{PS} 1 \Delta \mathrm{e} 9$ animals (Table 1), the numbers of primary, secondary, and tertiary lysosomes per cell body and process were not significantly different with respect to amyloid pathology (Tables 1 and 2).

\section{Effects of $A \beta$ on microglial cell stress}

The best characterized ultrastructural marker of cellular stress is ER stress, read out at high spatial resolution as a lumen dilation of ER and Golgi apparatus cisternae. It has been described in several neurodegenerative diseases, including amyotrophic lateral sclerosis and $\mathrm{AD}$ [63, 64]. ER dilation is also characteristic of the dark microglia, a phenotype upregulated in disease contexts including AD pathology [36]. In the current study, we were interested in investigating intermediate stages between the typical microglia and dark ones. Various hallmarks of dark microglia were examined in the ventral hippocampus CA1 strata radiatum and lacunosum-moleculare of wild-type and $\mathrm{APP}^{\mathrm{Swe}}-\mathrm{PS} 1 \Delta \mathrm{e} 9$ animals, including the presence of dilated ER among microglial cell bodies and processes, the alteration to organelles including mitochondria, the condensation of cytoplasmic and nucleoplasmic contents (thought to result in a dark/ electron-dense appearance), and the loss of heterochromatin pattern.

Healthy ER is characterized by long stretches of parallel membranes with very little space between them. On the other hand, dilated ER appears with non-parallel membranes containing bloated stretches of electron-lucent materials (Fig. 5a, b). When comparing the prevalence of dilated ER among microglial cell bodies from $\mathrm{APP}^{\mathrm{Swe}}-\mathrm{PS} 1 \Delta \mathrm{e} 9$ animals and wild-type controls, there was no difference between genotypes (Table 1). After separating our analysis into healthy, neuronal dystrophy, or $\mathrm{fA} \beta$ plaque subregions, it became clear that an increase in dilated ER was present, but only in plaque-associated microglial cell bodies (Fig. 5e).

In addition to studying dilated ER in microglial cell bodies and processes, we investigated the presence of lipidic inclusions in microglia from WT and $\mathrm{APP}^{\mathrm{Swe}}$-PS1 $1 \mathrm{e} 9$ animals. Lipidic inclusions are dynamic clusters of lipid droplets, made up of a cholesterol and triglyceride core surrounded by a phospholipid monolayer, which house numerous signaling proteins, and are visible in electron microscopy as circular droplets of homogeneous electron density (Fig. 5a, c, d). Lipid droplets are actively formed in microglial cells that respond to pro-inflammatory cytokines and may represent a marker of cellular metabolic stress or an early hallmark of neuroinflammation [56]. The number of lipidic inclusions significantly increased in microglial processes from $\mathrm{APP}^{\mathrm{Swe}}$-PS1 $1 \mathrm{e} 9$ animals, especially nearby plaques (Fig. 5f, g).

In addition, microglial cell bodies often displayed reduced IBA1 immunoreactivity in the $\mathrm{APP}^{\mathrm{Swe}}-\mathrm{PS} 1 \triangle \mathrm{e} 9$ animals, across the three subregions (see Figs. 5a, c and 1), while the dark microglia were previously shown to downregulate IBA1 in the same hippocampal region of 14-month-old $\mathrm{APP}^{\mathrm{Swe}}$-PS1 $\triangle \mathrm{e} 9$ mice [36]. Microglial cell bodies endowed with dilated ER, as observed around the plaques mainly, sometimes appeared darker than the typical microglia (see Figs. 1c and 5a), suggesting slight condensation of their cytoplasmic and nucleoplasmic contents. These darker cells however had a clearly defined heterochromatin pattern, as compared with the dark microglia.

\section{Microglial ultrastructure in human cases of $A D$}

In an effort to determine the clinical relevance of our microglial ultrastructure studies conducted in mouse hippocampus, we investigated tissue gathered from the hippocampi of two post-mortem AD cases. Fifty-micrometer-thick sections containing the hippocampus were 


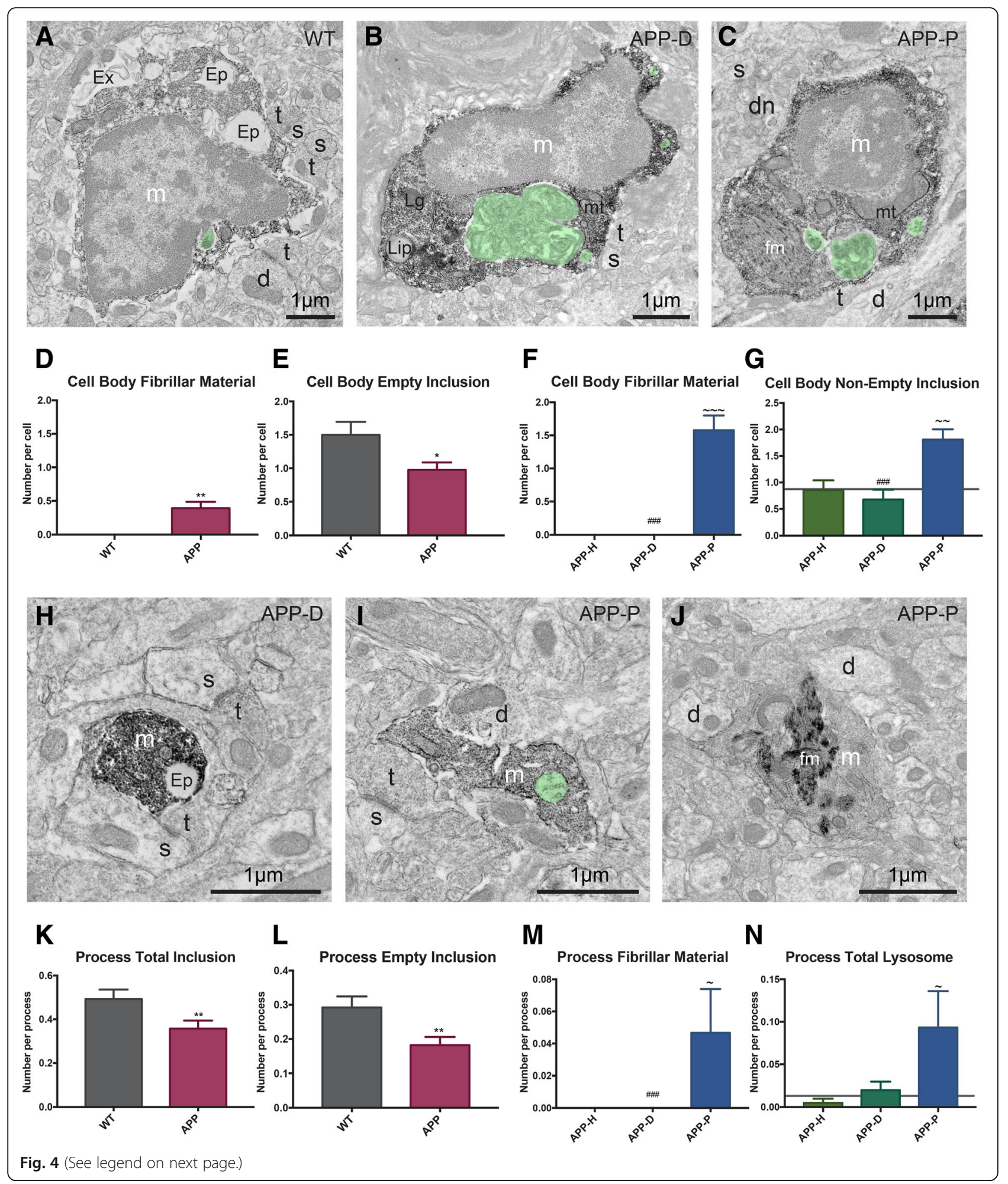


(See figure on previous page.)

Fig. 4 Distinct changes in microglial phagolysosomal system of APP ${ }^{\text {Swe }}$-PS1 1 e9 animals. a-c Example of IBA1-positive microglial cell bodies containing empty inclusions, non-empty inclusions (pseudocolored in green), or fibrillar materials in wild-type (WT; a), APP-D (b), or APP-P (c) subregions of ventral hippocampus CA1. d Quantification of fibrillar materials phagocytosis by microglial cell bodies in APP ${ }^{\text {Swe }}$-PS1 $\Delta \mathrm{e} 9$ mice. e Quantification of cell bodies containing empty phagocytic inclusions in APPSwe_PS1 1 e9 mice. $\mathbf{f}$ Only microglial cell bodies in APP-P regions contained fibrillar materials. $\mathbf{g}$ Cell bodies in APP-P regions contained increased numbers of non-empty phagocytic inclusions. $\mathbf{h}$-j IBA1-positive microglial processes containing various phagocytic inclusions in APP-P and APP-D subregions. $\mathbf{k}$ Quantification of microglial process inclusions in WT and APP ${ }^{\text {Swe }}$-PS1 1 e9 mice. I Quantification of microglial processes containing empty inclusions in APP Swe - PS1 $\Delta$ e9 mice. m Only microglial processes in APP-P regions contained fibrillar materials. $\mathbf{n}$ Quantification of lysosome numbers in APP-H, APP-D, and APP-P subregions associated microglial processes. $d$ dendrite, Ep empty phagocytic inclusion, $d n$ dystrophic neurite, $f m$ fibrillar material, Ex extracellular space pocket containing debris, $m$ microglia, $m t$ mitochondrion, $s$ dendritic spine, $t$ axon terminal. Error bars represent mean \pm SEM. WT levels are shown on the subregion graphs by a gray horizontal line. $n=50$ processes per condition for APP-H, APP-D, and APP-P and 70 processes per animal for WT animals, $n=7-15$ cells per condition for all conditions, and data was collected from $N=3-4$ animals per condition. * denotes difference from WT, $\sim$ denotes difference from APP-H, \# denotes difference from APP-P ${ }^{*}, \sim p<0.05 ;{ }^{* *}, \sim p<0.01 ;{ }^{* * *}, \sim \sim \sim \# \# p 0.001$
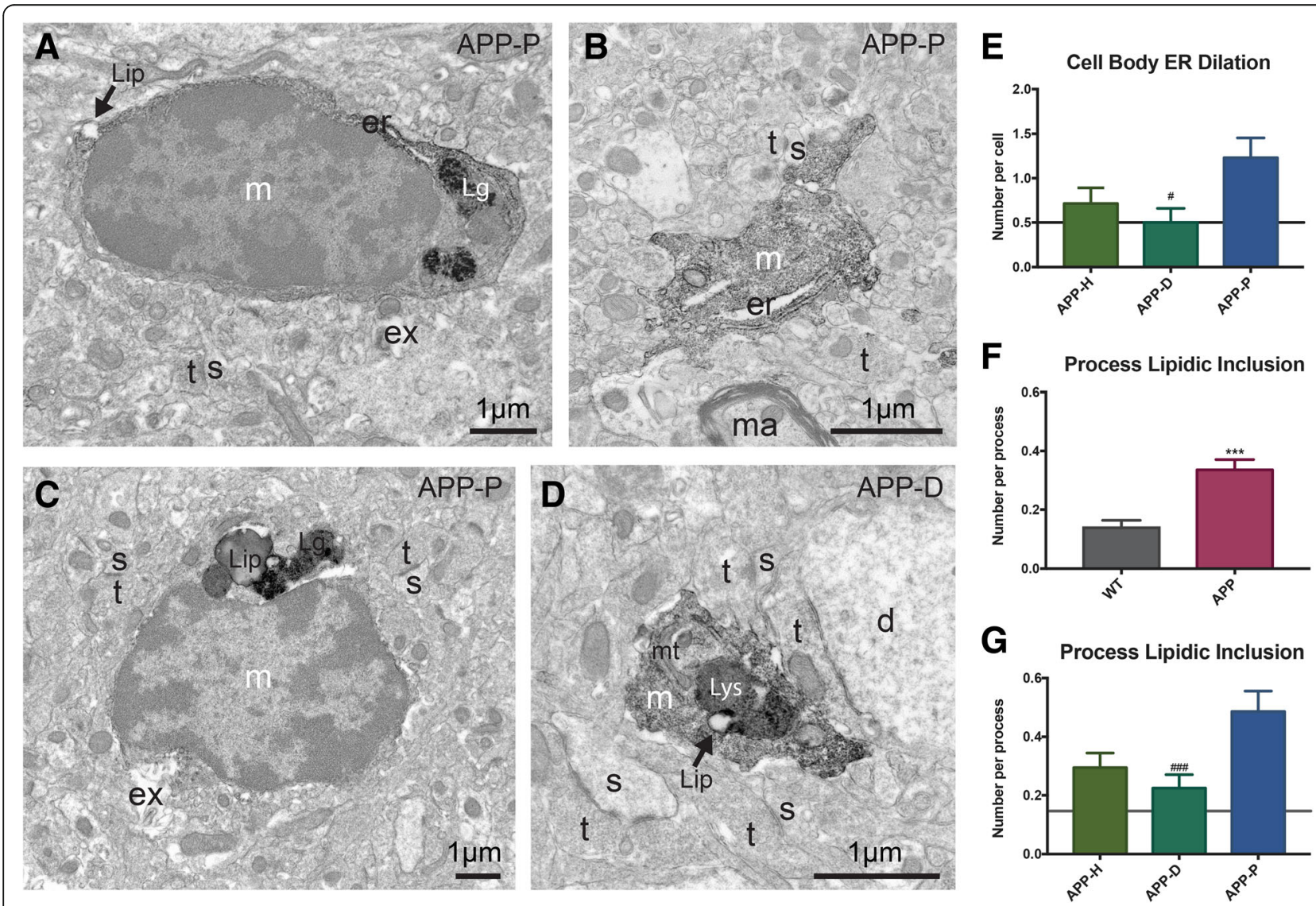

Fig. 5 Microglia in APPSwe-PS1 1 e9 animals display increased signs of cellular stress. a Example of IBA1-positive cell body imaged in the ventral hippocampus CA1 of the APP-P subregion that displays ER dilation, a lipidic inclusion and lipofuscin granules. $\mathbf{b}$ Example of microglial process in the APP-P subregion showing ER dilation. c IBA1-positive microglial cell body contacting extracellular space pockets with debris and containing lipidic inclusions and lipofuscin granules. $\mathbf{d}$ Microglial cell process containing a lysosome and a lipidic inclusion. $d$ dendrite, er endoplasmic reticulum, Ex extracellular space pocket containing debris, $L g$ lipofuscin granule, Lip lipidic inclusion, Lys lysosome, $m$ microglia, ma myelinated axon, $m t$ mitochondrion, $s$ dendritic spine, $t$ axon terminal. e Quantification of dilated ER in microglial cell bodies from APP-H, APP-D, and APP-P subregions of APPSwe-PS1 $\triangle$ e9 mice. f Microglial processes in APP Swe $-P S 1 \Delta$ e9 animals are more likely to contain lipidic inclusions than those in WT animals. $\mathbf{g}$ Quantification of lipid body inclusions in microglial processes from APP-H, APP-D, and APP-P subregions. $n=50$ processes per condition for APP-H, APP-D, and APP-P and 70 processes per animal for WT animals, $n=7-15$ cells per condition for all conditions, and data was collected from $N=3-4$ animals per condition. Error bars represent mean \pm SEM. WT levels are shown on the subregion graphs by a gray horizontal line. \#p<0.05; ${ }^{* *}$,\#\#\#p<0.001. ${ }^{*}$ denotes difference from WT animal, \# denotes difference from APP-P region 
Table 1 Ultrastructural analysis of microglial cell bodies in wildtype (WT) littermate controls versus APP ${ }^{\text {Swe }}$-PS1 1 e9 mice

\begin{tabular}{lll}
\hline & WT & APP \\
& Mean \pm SEM & Mean \pm SEM \\
\hline Area $\left(\mu m^{2}\right)$ & $17.53 \pm 1.06$ & $22.64 \pm 1.13^{*}$ \\
Perimeter $(\mu \mathrm{m})$ & $21.98 \pm 1.01$ & $25.71 \pm 1.41$ \\
Circularity (a.u.) & $0.482 \pm 0.02$ & $0.487 \pm 0.018$ \\
Roundness (a.u.) & $0.594 \pm 0.027$ & $0.606 \pm 0.187$ \\
Solidity (a.u.) & $0.838 \pm 0.0139$ & $0.838 \pm 0.01$ \\
Lipid body ( $n)$ & $0.667 \pm 0.159$ & $0.488 \pm 0.10$ \\
Fibrillar materials inclusion $(n)$ & 0 & $0.390 \pm 0.096^{* *}$ \\
Phagocytic (\%) & $78.6 \pm 6.40$ & $79.3 \pm 4.50$ \\
Total inclusion $(n)$ & $1.810 \pm 0.187$ & $1.707 \pm 0.123$ \\
Non-empty inclusion $(n)$ & $0.833 \pm 0.148$ & $1.024 \pm 0.119$ \\
Empty inclusion $(n)$ & $1.50 \pm 0.194$ & $0.976 \pm 0.111$ \\
ER dilation $(n)$ & $0.50 \pm 0.11$ & $0.80 \pm 0.11$ \\
Extracellular debris $(n)$ & $1.667 \pm 0.212$ & $0.854 \pm 0.131^{* *}$ \\
Primary lysosome $(n)$ & $0.1667 \pm 0.108$ & $0.171 \pm 0.064$ \\
Secondary lysosome $(n)$ & $0.762 \pm 0.186$ & $0.548 \pm 0.109$ \\
Tertiary lysosome $(n)$ & $0.643 \pm 0.17$ & $0.402 \pm 0.096$ \\
Total lysosome $(n)$ & $1.00 \pm 0.21$ & $0.89 \pm 0.138$ \\
\hline
\end{tabular}

a.u. arbitrary unit, $n$ number per microglial cell body stained against IBA1 to identify microglial cell bodies and processes. Occasional $\mathrm{fA} \beta$ plaques were observed (Fig. 6a, b), with abundant dystrophic neurites (Fig. 6a$d, h, i)$, recognized by their accumulation of small, regularly packed dense bodies, and numerous autophagic vacuoles [65]. This identification of $\mathrm{fA} \beta$ plaques and dystrophic neurites in human samples is consistent with the literature [65-68]. As such, the tissues we investigated from $\mathrm{AD}$ individuals closely paralleled the subregions of $\mathrm{fA} \beta$ plaques and neuronal dystrophy that were analyzed in $\mathrm{APP}^{\text {Swe }}$-PS1 $1 \mathrm{e} 9$ mice.

Microglia in human AD cases were found to be immunoreactive for IBA1 in both their processes and cell body, and they displayed the same characteristic nuclei described in mice (Fig. 6c, f). Microglial processes were often seen to contact dystrophic neurites and dendritic spines (Fig. 6d, g-j). Interestingly, microglial processes were observed making several contacts and nearly completely encircling multiple sides of a dystrophic neurite containing an accumulation of autophagic vacuoles (Fig. 6g). Microglia in human tissue from patients who suffered from $A D$ were also phagocytic, with many processes displaying one or more phagocytic inclusions (Fig. 6h-j). These phagocytic inclusions appeared either empty or non-empty, consistent with the inclusions described in mouse microglia. Lysosomes were also frequently observed in the human microglial processes, showing intact granular structure and often juxtaposing

Table 2 Ultrastructural analysis of microglial cell bodies in healthy (APP-H), dystrophic (APP-D), and plaque-associated with dystrophy (APP-P) regions of APP ${ }^{\text {Swe }}$-PS1 $\triangle \mathrm{e} 9$ mice

\begin{tabular}{|c|c|c|c|}
\hline & APP-H & APP-D & APP-P \\
\hline & Mean \pm SEM & Mean \pm SEM & Mean \pm SEM \\
\hline Area $\left(\mu m^{2}\right)$ & $19.58 \pm 1.53$ & $21.52 \pm 1.80$ & $27.15 \pm 2.38 \sim$ \\
\hline Perimeter $(\mu \mathrm{m})$ & $23.08 \pm 1.24$ & $23.87 \pm 1.64$ & $30.5 \pm 3.76$ \\
\hline Circularity (a.u.) & $0.482 \pm 0.026$ & $0.519 \pm 0.033$ & $0.459 \pm 0.034$ \\
\hline Roundness (a.u.) & $0.546 \pm 0.03$ & $0.647 \pm 0.032$ & $0.625 \pm 0.031$ \\
\hline Solidity (a.u.) & $0.836 \pm 0.018$ & $0.856 \pm 0.018$ & $0.822 \pm 0.194$ \\
\hline Lipid body $(n)$ & $0.75 \pm 0.22$ & $0.429 \pm 0.158$ & $0.269 \pm 0.142$ \\
\hline Fibrillar materials inclusion ( $n$ ) & 0 & 0 & $1.577 \pm 0.223 \sim \sim \# \# \#$ \\
\hline Phagocytic (\%) & $0.75 \pm 0.083$ & $0.786 \pm 0.079$ & $0.846 \pm 0.072$ \\
\hline Total inclusion (n) & $1.536 \pm 0.209$ & $1.536 \pm 0.215$ & $2.077 \pm 0.228$ \\
\hline Non-empty inclusion (n) & $0.857 \pm 0.18$ & $0.679 \pm 0.186$ & $1.808 \pm 0.192 \sim \sim \# \#$ \\
\hline Empty inclusion $(n)$ & $0.857 \pm 0.191$ & $1.071 \pm 0.205$ & $1.00 \pm 0.184$ \\
\hline ER dilation $(n)$ & $0.714 \pm 0.177$ & $0.500 \pm 0.159$ & $1.231 \pm 0.224 \#$ \\
\hline Extracellular debris $(n)$ & $0.429 \pm 0.174$ & $1.179 \pm 0.236 \sim$ & $0.962 \pm 0.251$ \\
\hline Primary lysosome $(n)$ & $0.286 \pm 0.162$ & $0.174 \pm 0.050$ & $0.154 \pm 0.091$ \\
\hline Secondary lysosome $(n)$ & $0.679 \pm 0.21$ & $0.50 \pm 0.174$ & $0.462 \pm 0.177$ \\
\hline Tertiary lysosome $(n)$ & $0.75 \pm 0.213$ & $0.321 \pm 0.146$ & $0.115 \pm 0.085 \sim$ \\
\hline Total lysosome (n) & $1.25 \pm 0.27$ & $0.714 \pm 0.22$ & $0.577 \pm 0.185$ \\
\hline
\end{tabular}

a.u. arbitrary unit, $n$ number per microglial cell body. significant difference from APP-H; \# significant difference from APP-D 
Table 3 Ultrastructural analysis of microglial processes in wildtype (WT) littermate controls versus APP ${ }^{\text {Swe }}$-PS1 1 e9 mice

\begin{tabular}{|c|c|c|}
\hline & WT & APP \\
\hline & Mean \pm SEM & Mean \pm SEM \\
\hline Area $\left(\mu m^{2}\right)$ & $0.4111 \pm 0.021$ & $0.3957 \pm 0.020$ \\
\hline Perimeter $(\mu \mathrm{m})$ & $3.476 \pm 0.13$ & $3.409 \pm 0.13$ \\
\hline Circularity (a.u.) & $0.465 \pm 0.1$ & $0.499 \pm 0.01^{*}$ \\
\hline Roundness (a.u.) & $0.483 \pm 0.009$ & $0.508 \pm 0.009$ \\
\hline Solidity (a.u.) & $0.761 \pm 0.008$ & $0.780 \pm 0.007^{*}$ \\
\hline Lipidic inclusion ( $n$ ) & $0.139 \pm 0.025$ & $0.336 \pm 0.035^{* * *}$ \\
\hline Fibrillar materials inclusion ( $n$ ) & 0 & $0.0133 \pm 0.007$ \\
\hline Phagocytic process (\%) & $0.3179 \pm 0.024$ & $0.2289 \pm 0.02$ \\
\hline Total inclusion ( $n$ ) & $0.4923 \pm 0.043$ & $0.3578 \pm 0.037$ \\
\hline Non-empty inclusion $(n)$ & $0.210 \pm 0.026$ & $0.189 \pm 0.027$ \\
\hline Empty inclusion $(n)$ & $0.292 \pm 0.032$ & $0.182 \pm 0.024$ \\
\hline ER dilation $(n)$ & $0.021 \pm 0.008$ & $0.04 \pm 0.009$ \\
\hline Extracellular debris $(n)$ & $0.380 \pm 0.038$ & $0.249 \pm 0.027^{*}$ \\
\hline Total lysosome $(n)$ & $0.0153 \pm 0.0062$ & $0.0422 \pm 0.015$ \\
\hline Primary lysosome $(n)$ & $0.005 \pm 0.003$ & $0.009 \pm 0.007$ \\
\hline Secondary lysosome $(n)$ & $0.01 \pm 0.005$ & $0.03 \pm 0.009$ \\
\hline Tertiary lysosome $(n)$ & 0 & $0.016 \pm 0.008$ \\
\hline Encircled A $\beta(n)$ & 0 & $0.016 \pm 0.009$ \\
\hline Encircled synaptic element ( $n$ ) & $0.085 \pm 0.02$ & $0.20 \pm 0.03^{* *}$ \\
\hline Encircled dendritic spine $(n)$ & $0.06 \pm 0.016$ & $0.10 \pm 0.018^{*}$ \\
\hline Encircled axonal terminal $(n)$ & $0.02 \pm 0.008$ & $0.08 \pm 0.01^{* * *}$ \\
\hline Encircled degraded structure $(n)$ & $0.015 \pm 0.007$ & $0.029 \pm 0.009$ \\
\hline
\end{tabular}

a.u. arbitrary unit, $n$ number per microglial process

vesicular inclusions, suggesting a probable fusion to produce a phagolysosome (Fig. 6j). In addition, human microglial cell bodies and processes frequently associated with pockets of extracellular space that contained cellular debris, at various stages of degradation, supporting microglial involvement with the removal of extracellular debris (Fig. $6 c-j$ ). Microglia in human AD cases thus recapitulate several ultrastructural characteristics seen in the mouse model, particularly their intimate interactions with fA $\beta$ plaques, dystrophic neurites, and dendritic spines.

\section{Discussion}

Unraveling the role of microglia has been complicated by the heterogeneity displayed by these cells across brain regions, stages of the lifespan, and contexts of health and disease. The past decade has been a boon in the description of microglial phenotypic diversity and plasticity, using in vivo two-photon microscopy, single-cell RNA sequencing, and positron emission tomography to find hotspots of microglial activity within the human brain [69]. However, these techniques have been unable to investigate intimate microglial interactions with their surrounding brain environment. We have utilized TEM and SEM in order to uncover region-specific roles of microglia in the $\mathrm{APP}^{\mathrm{Swe}}-\mathrm{PS} 1 \Delta \mathrm{e} 9$ mouse model of $\mathrm{AD}$ pathology. Our data revealed striking ultrastructural differences of microglia among ventral hippocampus CA1 subregions containing $\mathrm{fA} \beta$ plaques, dystrophic neurons, or appearing ultrastructurally healthy, from $\mathrm{APP}^{\mathrm{Swe}}-\mathrm{PS} 1 \Delta \mathrm{e} 9$ mice, versus wild-type littermate controls. These findings were qualitatively replicated in two individuals who suffered from AD (Braak stage 5).

By separating AD pathology into separate subregions (healthy, dystrophic, and plaque-associated), we were able to discern subtle, but statistically significant, changes of microglial cell body and process morphology. Microglial cell bodies close to $f A \beta$ plaques were larger than in any other tissue investigated. Microglial processes profiles were also rounder and increased their solidity in $\mathrm{AD}$ model mice, regardless of dystrophic neurons or plaques proximity. These findings are concordant with the microglial morphological changes that were described at the light level in mouse models of amyloid pathology [70], and with the two-photon in vivo imaging studies demonstrating microglia from $\mathrm{AD}$ mouse models have reduced process motility $[71,72]$.

Our analyses in healthy subregions of hippocampus devoid of $\mathrm{fA} \beta$ plaque and dystrophic neurons revealed microglial characteristics of reduced extracellular degradation, accompanied by increased encirclement of dendritic spines. Studies in humans with mild cognitive impairment and in mouse models of $\mathrm{AD}$ have uncovered links between memory impairment and hyperactive neuronal networks within the hippocampus [73-75]. The loss of dendritic spines in the CA1 strata radiatum and lacunosum-moleculare is a leading mechanism linked to neuronal network hyperactivity in 10- to 14-month-old ARTE10 model mice [3]. Interestingly, the encirclement of dendritic spines was validated using our human $\mathrm{AD}$ hippocampal samples. It is thus tempting to hypothesize that microglia' increased contacts with neurons and synapses could be exacerbating cognitive impairment. Numerous in vitro and in vivo studies across various models of $\mathrm{AD}$ have identified profound synaptic deficits in response to small oligomeric and $\mathrm{sA} \beta[8]$. Increased levels of $\mathrm{sA} \beta$ are hypothesized to predispose neurons to both hyperactivity and excitotoxicity, which are associated with increases in local microglial response [9, 76]. Recent human studies have even implicated $\mathrm{fA} \beta$ plaques as amyloid sinks which lowered levels of circulating $\mathrm{sA} \beta$, thus preventing synaptic impairment early in the disease pathology [77]. These changes of functional plasticity and excitability are not visible at the ultrastructural level without performing complex and extensive synaptic analysis, and are the focus of future investigations. 
Table 4 Ultrastructural analysis of microglial processes in healthy (APP-H), dystrophic (APP-D), and plaque and dystrophy (APP-P) containing regions of APP ${ }^{\text {Swe }}$-PS $1 \Delta \mathrm{e} 9$ mice

\begin{tabular}{|c|c|c|c|}
\hline & APP-H & APP-D & APP-P \\
\hline & Mean \pm SEM & Mean \pm SEM & Mean \pm SEM \\
\hline Area $\left(\mu m^{2}\right)$ & $0.361 \pm 0.026$ & $0.451 \pm 0.033$ & $0.485 \pm 0.037$ \\
\hline Perimeter $(\mu \mathrm{m})$ & $3.333 \pm 0.197$ & $3.575 \pm 0.2$ & $3.317 \pm 0.209$ \\
\hline Circularity (a.u.) & $0.486 \pm 0.016$ & $0.501 \pm 0.017$ & $0.488 \pm 0.018$ \\
\hline Roundness (a.u.) & $0.485 \pm 0.014$ & $0.527 \pm 0.014$ & $0.492 \pm 0.016$ \\
\hline Solidity (a.u.) & $0.768 \pm 0.012$ & $0.789 \pm 0.012$ & $0.775 \pm 0.125$ \\
\hline Lipidic inclusion (n) & $0.295 \pm 0.050$ & $0.225 \pm 0.046$ & $0.487 \pm 0.07 \# \#$ \\
\hline Fibrillar materials inclusion ( $n$ ) & 0 & 0 & $0.047 \pm 0.027 \sim \#$ \\
\hline Phagocytic process (\%) & $0.2 \pm 0.028$ & $0.255 \pm 0.031$ & $0.24 \pm 0.035$ \\
\hline Total inclusion ( $n)$ & $0.295 \pm 0.046$ & $0.4 \pm 0.056$ & $0.38 \pm 0.687$ \\
\hline Non-empty inclusion ( $n$ ) & $0.115 \pm 0.029$ & $0.19 \pm 0.038$ & $0.193 \pm 0.041$ \\
\hline Empty inclusion (n) & $0.18 \pm 0.035$ & $0.21 \pm 0.04$ & $0.147 \pm 0.038$ \\
\hline ER dilation $(n)$ & $0.025 \pm 0.011$ & $0.05 \pm 0.154$ & $0.033 \pm 0.0175$ \\
\hline Extracellular debris $(n)$ & $0.24 \pm 0.04$ & $0.255 \pm 0.039$ & $0.24 \pm 0.047$ \\
\hline Total lysosome $(n)$ & $0.005 \pm 0.005$ & $0.002 \pm 0.01$ & $0.0933 \pm 0.04 \sim$ \\
\hline Primary lysosome $(n)$ & 0 & $0.02 \pm 0.016$ & 0 \\
\hline Secondary lysosome $(n)$ & $0.005 \pm 0.005$ & $0.01 \pm 0.007$ & $0.06 \pm 0.027 \sim$ \\
\hline Tertiary lysosome $(n)$ & 0 & $0.01 \pm 0.007$ & $0.033 \pm 0.024$ \\
\hline Encircled A $A(n)$ & 0 & 0 & $0.047 \pm 0.027 \sim \#$ \\
\hline Encircled synaptic element ( $n$ ) & $0.345 \pm 0.067$ & $0.215 \pm 0.049$ & $0.14 \pm 0.038 \sim$ \\
\hline Encircled dendritic spine $(n)$ & $0.185 \pm 0.038$ & $0.115 \pm 0.028$ & $0.08 \pm 0.026$ \\
\hline Encircled axonal terminal $(n)$ & $0.155 \pm 0.028$ & $0.09 \pm 0.024$ & $0.053 \pm 0.018$ \\
\hline Encircled degraded structure $(n)$ & $0.025 \pm 0.013$ & $0.04 \pm 0.017$ & $0.006 \pm 0.006$ \\
\hline
\end{tabular}

a.u. arbitrary unit, $n$ number per microglial process. significant difference from APP-H; \# significant difference from APP-D

While our studies separate plaque-associated tissue from apparently healthy tissue, we cannot overlook the probability that soluble amyloid was present. Amyloid plaques are electron-dense, but soluble amyloid is not distinguishable in EM without immunostaining. Three-dimensional EM studies focused on $\mathrm{fA} \beta$-neuronal interactions found intimate contacts of amyloid with dendritic membranes in the hippocampus of $3 \mathrm{XTg}$ model mice and in the prefrontal cortex of aged canines [78]. It is possible the phenotypic changes we identified in "healthy" hippocampal regions of our transgenic mice are driven by soluble amyloid. This is particularly relevant when interpreting the increased microglial encirclement of dendritic spines in $\mathrm{APP}^{\mathrm{Swe}}-\mathrm{PS} 1 \Delta \mathrm{e} 9$ mice, and microglial interactions with the synaptic neuropil observed in the human AD hippocampus. Additionally, as our human data only focuses on microglial interactions in $\mathrm{AD}$, we cannot overlook the possibility that some of the microglial ultrastructural changes may be driven by normal aging and not solely due to $\mathrm{AD}$ pathology.

Our studies have shown that microglial processes in subregions with $\mathrm{fA} \beta$ plaques contain intracellular fibrillar materials, contrary to microglia among dystrophic only or healthy subregions. This is in line with numerous in vitro and in vivo studies demonstrating microglial capacity to phagocytose both soluble and fibrillar forms of $A \beta$ [79-81]. This finding additionally suggests that microglia may remain in close proximity to amyloid after recognition via cell-surface receptor complexes, as supported by previous two-photon in vivo imaging observations in the cerebral cortex of AD model mice [71]. While microglia are proficient at phagocytosing amyloid, when presented with chronic high levels of $\mathrm{fA} \beta$ such as measured in AD mouse models and human pathology, their phagolysosomal system becomes overloaded and unable to properly degrade the $f A \beta$ [82]. In fact, in vitro studies have found intact $f A \beta$ remains within microglia as long as 20 days after incubation with amyloid [83]. This may explain both the high prevalence of fibrillar materials within microglial processes and their increased numbers of lysosomes we reported. Plaque-associated microglial processes particularly had increased numbers of secondary lysosomes, which are often referred to as phagolysosomes-the organelles created 

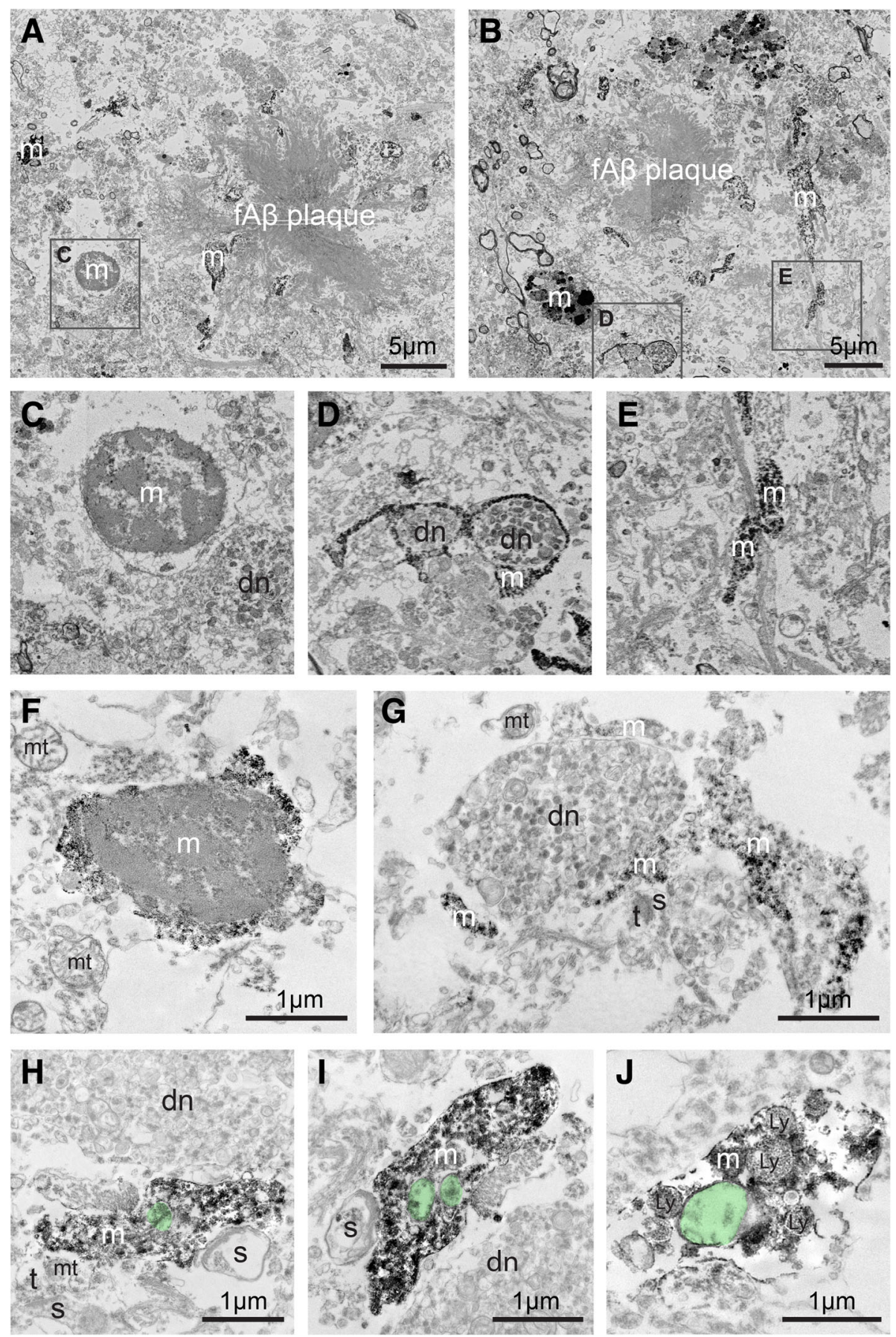

Fig. 6 Microglial ultrastructure in post-mortem hippocampal samples from two human AD patients. a, b Examples of IBA1-immunopositive microglial cell bodies and processes surrounding $f A \beta$ plaques in the post-mortem hippocampus from an individual diagnosed with AD (Braak stage 5). c-e Insets from A and B, showing: $\mathbf{c}$ a microglial cell body contacting a dystrophic neurite, $\mathbf{d}$ a microglial process encircling two dystrophic neurites, and $\mathbf{e}$ another microglial process wrapping around other neuropil elements. $\mathbf{f}-\mathbf{j}$ IBA1-immunopositive microglial cell body and processes from post-mortem hippocampal tissue from a second individual diagnosed with AD (also Braak stage 5). g-j Microglial processes seen making contacts with dystrophic neurites and dendritic spines, some of them receiving synapses from axon terminals, as well as containing phagocytic inclusions and lysosomes. $d n$ dystrophic neurite, Ly lysosome, $m$ microglia, $m t$ mitochondrion, $s$ dendritic spine, $t$ axon terminal. Non-empty phagocytic inclusions are pseudocolored in green 
when phagosomes and lysosomes fuse to reduce $\mathrm{pH}$ and degrade internalized materials $[62,84]$. Interestingly, failure to acidify phagolysosomal compartments has been implicated in the $f A \beta$ overloading of microglia [85]. This failure may also explain the differences in microglial phagocytosis and different ratios of empty versus non-empty inclusions between cell bodies of seemingly healthy versus dystrophic versus plaque-associated subregions of CA1. Perhaps the increase in non-empty microglial inclusions seen in plaque-associated areas is actually due to an impaired digestion of the phagocytosed amyloid.

It is important to note, however, that because our TEM imaging protocol was conducted on single ultrathin sections, we cannot overlook the possibility that phagocytic vesicles may represent pockets of extracellular material not yet fully engulfed, or interdigitations between microglial processes and surrounding neuropil. 3D-EM reconstructions of microglia previously showed no intracellular amyloid in the cerebral cortex of the APP23 mouse model [86]. However, the differences in mouse model, age of animals, studied region, and sample preparation make it difficult to compare with our own findings. Additionally, this work did not investigate microglial phagocytosis within the synaptic neuropil, and focused on $f A \beta$ alone. It is known that microglia readily internalize and degrade numerous targets in healthy and diseased tissue, and their identification should be the focus of future nano-scale resolution studies [87-89]. Other microglial phenotypes or subtypes, such as dark microglia, and others showing intermediate stages of subcellular anomalies (e.g., ER dilation, condensation of cytoplasmic and nucleoplasmic contents), as described in this study, might also behave differently toward amyloid.

Recent transcriptome analysis of human AD tissue lastly revealed similarities and differences in the innate immune response compared to animal models of AD [90]. Nearly all amyloid mouse models of AD yield excessive overexpression of human APP protein, often with multiple mutations driving $A \beta_{42}$ expression to drive plaque formation [91]. These models do not express intracellular tau depositions and often do not recapitulate the extensive neuronal loss documented in human AD cases. It is thus crucial to verify findings in human studies whenever possible. For the first time, we have investigated microglial relationships with the synaptic neuropil at ultrastructural resolution in post-mortem hippocampal tissue derived from individuals who suffered from $A D$, which allowed us to validate qualitatively our findings with respect to microglial association with extracellular debris and $\mathrm{fA} \beta$ plaques, encirclement of dystrophic neurites and dendritic spines, as well as phagocytic inclusions.

\section{Conclusions}

Overall, our findings shed more light on microglial ultrastructural diversity in AD amyloid pathology, supporting the previous findings of morphological alterations (enlarged cell bodies), impaired process motility, and phagocytic capacity that were obtained at the light level. This heterogeneity in microglial ultrastructure is paralleled with the diversity recently discovered in single-cell RNAseq studies. In addition, increased microglial process interactions with dendritic spines were uncovered among subregions of AD model mice still unaffected by neuronal dystrophy and plaque pathology, paralleling the functional alterations of neuronal network activity known to be driven by soluble amyloid. Intermediate stages between the typical and dark microglia were further described, raising the intriguing possibility that these dark cells could derive from typical microglia in a stepwise fashion, similarly to the DAM and $M G n D$ recently identified. Future studies are warranted to determine the physiological relevance of these microglial alterations, phenotypic transformations, or subtype expansion, together with their outcome on synaptic loss and neurodegeneration in $\mathrm{AD}$, across different stages of pathology and brain regions.

\section{Abbreviations \\ AD: Alzheimer's disease; A $A$ : Amyloid beta; DAB: Diaminobenzidine; DAM: Disease-associated microglia; ER: Endoplasmic reticulum; fAB: Fibrillar amyloid beta; GWAS: Genome-wide association study; $\mathrm{H}_{2} \mathrm{O}_{2}$ : Hydrogen peroxide; IBA1: Ionized calcium binding adaptor molecule 1; IL- \\ 1ß: Interleukin-1 beta; MGND: Microglia neurodegenerative phenotype; PB: Phosphate buffer; PBS: Phosphate-buffered saline; RT: Room temperature; SAB: Soluble amyloid beta; SEM: Standard error of the mean; TBS: Tris- buffered saline; TNFa: Tumor necrosis factor alpha; TREM2: Triggering receptor expressed on myeloid cells 2}

\section{Acknowledgements}

We are grateful to Nathalie Vernoux for technical assistance and guidance with the experiments, Sammy Weiser Novak for his help developing our scanning electron microscopy techniques, and Julie-Christine Lévesque at the Bio-Imaging platform of the Infectious Disease Research Centre, funded by an equipment and infrastructure grant from the Canadian Foundation Innovation (CFI), as well as Martin Fuhrmann and Michael Heneka for discussing some of the findings.

\section{Funding}

H.E.H. was supported by a scholarship from the Lebanese Ministry of Education and Higher Education, K.B. by excellence scholarships from Université Laval and Fondation du CHU de Québec, and J.C.S. by a postdoctoral fellowship from Fonds de recherche du Québec - Santé. This work was funded by grants from The Banting Research Foundation, The Scottish Rite Charitable Foundation of Canada, and NEURON-ERANET (Traclnflam) awarded to M.E.T. S.R. and M.E.T. hold Canada Research Chairs of Neuroimmunology and Neuroimmune plasticity in health and therapy, respectively.

\section{Availability of data and materials}

The datasets generated and analyzed during the current study are available from the corresponding authors on reasonable request.

\section{Authors' contributions}

HEH collected tissues, performed experiments and data analysis, wrote the manuscript, and generated figures. JS designed experiments, performed data analysis, wrote and edited the manuscript, as well as generated figures. KB collected tissues and performed experiments. MP, LV, and SR provided 
tissues and contributed to the writing of the manuscript. MET designed experiments, generated figures, wrote and edited the manuscript. All authors read and approved the final manuscript.

\section{Ethics approval and consent to participate}

All experiments were approved and performed under the guidelines of the Institutional Animal Ethics Committees, in conformity with the Canadian Council on Animal Care guidelines as administered by the Animal Care Committee of Université Laval. Brain banking and post-mortem tissue handling procedures were approved by the Ethic Committee of the Institut Universitaire en santé mentale de Québec and by Université Laval. The brains examined in this study were obtained with written consent, and the analyses were performed in conformity with the Code of Ethics of the World Medical Association (Declaration of Helsinki).

\section{Consent for publication}

Not applicable.

\section{Competing interests}

The authors declare that they have no competing interests.

\section{Publisher's Note}

Springer Nature remains neutral with regard to jurisdictional claims in published maps and institutional affiliations.

\section{Author details}

${ }^{1}$ Axe neurosciences, Centre de recherche du CHU de Québec-Université Laval, 2705, boulevard Laurier, T2-50, Quebec, QC G1V 4G2, Canada. ²Département de psychiatrie et de neurosciences, Faculté de médecine, Université Laval, Quebec, QC, Canada. ${ }^{3}$ CERVO Brain Research Center, Quebec, QC, Canada. ${ }^{4}$ Département de médecine moléculaire, Faculté de médecine, Université Laval, Quebec, QC, Canada.

\section{Received: 19 December 2018 Accepted: 1 April 2019}

\section{Published online: 16 April 2019}

\section{References}

1. International AD. World Alzheimer Report 2016; 2016. p. 1-140.

2. Alzheimer Association. 2018 Alzheimer's disease facts and figures. Alzheimer's Dement. 2018:2018:1-88.

3. Sisková Z, Justus D, Kaneko H, Friedrichs D, Henneberg N, Beutel T, et al Dendritic structural degeneration is functionally linked to cellular hyperexcitability in a mouse model of Alzheimer's disease. Neuron Elsevier Inc. 2014;84:1023-33.

4. Terry RD, Masliah E, Salmon DP, Butters N, DeTeresa R, Hill R, et al. Physical basis of cognitive alterations in Alzheimer's disease: synapse loss is the major correlate of cognitive impairment. Ann Neurol. 1991;30:572-80.

5. O'Sullivan M, Ngo E, Viswanathan A, Jouvent E, Gschwendtner A, Saemann $P G$, et al. Hippocampal volume is an independent predictor of cognitive performance in CADASIL. Neurobiol Aging. 2009;30:890-7.

6. Mega MS, Small GW, XU ML, Felix J, Manese M, Tran NP, et al. Hippocampal atrophy in persons with age-associated memory impairment: volumetry within a common space. Psychosom Med. 2002;64:487-92.

7. Schuitemaker A, Kropholler MA, Boellaard R, van der Flier WM, Kloet RW, van der Doef TF, et al. Microglial activation in Alzheimer's disease: an, vol. 34. NBA: Elsevier Inc; 2013. p. 128-36.

8. Mucke L, Selkoe DJ. Neurotoxicity of amyloid-protein: synaptic and network dysfunction. Cold Spring Harb Perspect Med. 2012;2:a006338.

9. Ferreira ST, Lourenco MV, Oliveira MM, De Felice FG. Soluble amyloid-beta oligomers as synaptotoxins leading to cognitive impairment in Alzheimer's disease. Front Cell Neurosci. 2015;9:9498.

10. Selkoe DJ. Soluble oligomers of the amyloid $\beta$-protein impair synaptic plasticity and behavior. Behav Brain Res. 2008;192:106-13.

11. Cummings BJ, Su JH, Geddes JW, Van Nostrand WE, Wagner SL, Cunningham DD, et al. Aggregation of the amyloid precursor protein within degenerating neurons and dystrophic neurites in Alzheimer's disease. Neuroscience. 1992:48:763-77.

12. Adalbert $R$, Nogradi A, Babetto $E$, Janeckova $L$, Walker $S A$, Kerschensteiner $M$, et al. Severely dystrophic axons at amyloid plaques remain continuous and connected to viable cell bodies. Brain. 2008;132:402-16.
13. Koffie RM, Meyer-Luehmann M, Hashimoto T, Adams KW, Mielke ML, GarciaAlloza M, et al. Oligomeric amyloid beta associates with postsynaptic densities and correlates with excitatory synapse loss near senile plaques. Proc Natl Acad Sci U S A. 2009;106:4012-7.

14. Lambert JC, Ibrahim-Verbaas CA, Harold D, Naj AC, Sims R, Bellenguez C, et al. Meta-analysis of 74,046 individuals identifies 11 new susceptibility loci for Alzheimer's disease. Nat Genet. 2013;45:1452-8.

15. Jonsson T, Stefansson H, Steinberg S, Jonsdottir I, Jonsson PV, Snaedal J, et al. Variant of TREM2 associated with the risk of Alzheimer's disease. N Engl J Med. 2013;368:107-16.

16. Griciuc A, Serrano-Pozo A, Parrado AR, Lesinski AN, Asselin CN, Mullin K, et al. Alzheimer's disease risk gene CD33 inhibits microglial uptake of amyloid beta. Neuron. 2013;78:631-43.

17. Doens D, Fernández PL. Microglia receptors and their implications in the response to amyloid $\beta$ for Alzheimer's disease pathogenesis. J Neuroinflammation. 2014;11: $1-14$

18. Meda L, Cassatella MA, Szendrei Gl, Otvos L, Baron P, Villalba M, et al. Activation of microglial cells by beta-amyloid protein and interferongamma. Nature. 1995;374:647-50.

19. Tan J, Town T, Paris D, Mori T, Suo Z, Crawford F, et al. Microglial activation resulting from CD40-CD40L interaction after beta-amyloid stimulation. Science. 1999;286:2352-5.

20. Hong S, Beja-Glasser VF, Nfonoyim BM, Frouin A, Li S, Ramakrishnan S, et al. Complement and microglia mediate early synapse loss in Alzheimer mouse models. Science. 2016;352(6286):712-6.

21. Khoury El JB, Moore KJ, Means TK, Leung J, Terada K, Toft M, et al. CD36 mediates the innate host response to beta-amyloid. J Exp Med. 2003;197:1657-66.

22. Zhao R, Hu W, Tsai J, Li W, Gan W-B. Microglia limit the expansion of $\beta$ amyloid plaques in a mouse model of Alzheimer'sdisease. Mol Neurodegener. 2017;12:1-11.

23. Wang Y, Ulland TK, Ulrich JD, Song W, Tzaferis JA, Hole JT, et al. TREM2mediated early microglial response limits diffusion and toxicity of amyloid plaques. J Exp Med. 2016;213:667-75.

24. Wildsmith KR, Holley M, Savage JC, Skerrett R, Landreth GE. Evidence for impaired amyloid $\beta$ clearance in Alzheimer's disease. Alzheimers Res Ther. 2013;5:33

25. ElAli $A$, Rivest $\mathrm{S}$. The role of $A B C B 1$ and $A B C A 1$ in beta-amyloid clearance at the neurovascular unit in Alzheimer's disease. Front Physiol. 2013;4:45.

26. Ries M, Sastre M. Mechanisms of A $\beta$ clearance and degradation by glial cells. Front Aging Neurosci. 2016;8:160.

27. Gosselin D, Link VM, Romanoski CE, Fonseca GJ, Eichenfield DZ, Spann NJ, et al. Environment drives selection and function of enhancers controlling tissue-specific macrophage identities. Cell. 2014;159:1327-40.

28. Gosselin D, Skola D, Coufal NG, Holtman IR, Schlachetzki JCM, Sajti E, et al. An environment-dependent transcriptional network specifies human microglia identity. Science. 2017;356:eaal3222

29. Tamboli IY, Barth E, Christian L, Siepmann M, Kumar S, Singh S, et al. Statins promote the degradation of extracellular amyloid \{beta\}-peptide by microglia via stimulation of exosome-associated insulin-degrading enzyme (IDE) secretion. J Biol Chem. 2010;285:37405-14.

30. Yan P, Hu X, Song H, Yin K, Bateman RJ, Cirrito JR, et al. Matrix metalloproteinase-9 degrades amyloid-beta fibrils in vitro and compact plaques in situ. J Biol Chem. 2006;281:24566-74.

31. Bisht K, Sharma K, Tremblay M-Ë. Chronic stress as a risk factor for Alzheimer's disease: roles of microglia-mediated synaptic remodeling, inflammation, and oxidative stress. Neurobiol Stress. 2018;9:9-21.

32. Keren-Shaul H, Spinrad A, Weiner A, Matcovitch-Natan O, DvirSzternfeld R, Ulland TK, et al. A unique microglia type associated with restricting development of Alzheimer's disease. Cell. Elsevier Inc. 2017;169:1-33

33. Krasemann S, Madore C, Cialic R, Baufeld C, Calcagno N, Fatimy El R, et al. The TREM2-APOE pathway drives the transcriptional phenotype of dysfunctional microglia in neurodegenerative diseases. Immunity Elsevier Inc. 2017:47:566-9.

34. Mathys H, Adaikkan C, Gao F, Young JZ, Manet E, Hemberg M, et al Temporal tracking of microglia activation in neurodegeneration at singlecell resolution. Cell Rep. 2017;21:366-80.

35. Hsieh CL, Koike M, Spusta SC, Niemi EC, Yenari M, Nakamura MC, et al. A role for TREM2 ligands in the phagocytosis of apoptotic neuronal cells by microglia. J Neurochem. 2009;109:1144-56. 
36. Bisht K, Sharma KP, Lecours C, Gabriela Sánchez M, Hajj El H, Milior G, et al. Dark microglia: a new phenotype predominantly associated with pathological states. Glia. 2016;64(5):826-39.

37. Borchelt DR, Ratovitski T, van Lare J, Lee MK, Gonzales V, Jenkins NA, et al. Accelerated amyloid deposition in the brains of transgenic mice coexpressing mutant presenilin 1 and amyloid precursor proteins. Neuron. 1997;19:939-45.

38. Malm T, Koistinaho J, Kanninen K. Utilization of APPswe/PS1dE9 transgenic mice in research of Alzheimer's disease: focus on gene therapy and cellbased therapy applications. Int J Alzheimers Dis. 2011;2011:517160.

39. Puoliväli J, Wang J, Heikkinen T, Heikkilä M, Tapiola T, van Groen T, et al. Hippocampal a beta 42 levels correlate with spatial memory deficit in APP and PS1 double transgenic mice. Neurobiol Dis. 2002;9:339-47.

40. McClean PL, Parthsarathy V, Faivre E, Holscher C. The diabetes drug liraglutide prevents degenerative processes in a mouse model of Alzheimer's disease. J Neurosci. 2011;31:6587-94.

41. Bisht K, Hajj El H, Savage JC, Sánchez MG, Tremblay M-Ė. Correlative light and electron microscopy to study microglial interactions with $\beta$-amyloid plaques. J Vis Exp. 2016;112:54060.

42. Wang J, Tanila H, Puoliväli J, Kadish I, van Groen T. Gender differences in the amount and deposition of amyloidbeta in APPswe and PS1 double transgenic mice. Neurobiol Dis. 2003;14:318-27.

43. Tremblay MÈ, Riad M, Majewska A. Preparation of mouse brain tissue for immunoelectron microscopy. J Vis Exp. 2010;(41):2021. https://doi.org/10. 3791/2021.

44. Paxinos G, Franklin KBJ. The Mouse Brain in Stereotaxic Coordinates. Orlando: Academic Press; 2004. https://books.google.ca/books?(seeid= EHy1QN1xv0gC\&printsec=frontcover\&source=gbs_ge_summary_r\&cad= $0 \# v=$ onepage \&q\&f=false).

45. Tremblay M-Ë, Lowery RL, Majewska AK. Microglial interactions with synapses are modulated by visual experience. PLoS Biol. 2010;8: e1000527.

46. Savage JC, Picard K, González-lbáñez F, Tremblay M-Ė. A brief history of microglial ultrastructure: distinctive features, phenotypes, and functions discovered over the past 60 years by electron microscopy. Front Immunol. 2018;9:803.

47. Simard AR, Soulet D, Gowing G, Julien J-P, Rivest S. Bone marrow-derived microglia play a critical role in restricting senile plaque formation in Alzheimer's disease. Neuron. 2006:49:489-502.

48. Deerinck T, Bushong EA, Thor A, H EM. NCMIR Methods for 3D EM: A new protocol for preparation of biological specimens for serial blockface scanning electron microscopy [Internet]. 2015. ncmir.ucsd.edu. [cited 2019 Feb 23]. Available from: https://ncmir.ucsd.edu/sbem-protocol. Accessed 8 Apr 2019.

49. De Duve C. The lysosome. Sci Am. 1963;208:64-72.

50. Holtzman E, Novikoff AB, Villaverde H. Lysosomes and GERL in normal and chromatolytic neurons of the rat ganglion nodosum. J Cell Biol. 1967:33:419-35.

51. Nandy K. Properties of neuronal lipofuscin pigment in mice. Acta Neuropathol. 1971;19:25-32.

52. Perlmutter LS, Barron E, Chui HC. Morphologic association between microglia and senile plaque amyloid in Alzheimer's disease. Neurosci Lett. 1990;119:32-6

53. Chavez-Valdez R, Flock DL, Martin LJ, Northington FJ. Endoplasmic reticulum pathology and stress response in neurons precede programmed necrosis after neonatal hypoxia-ischemia. Int J Dev Neurosci. 2016:48:58-70.

54. Haka AS, Barbosa-Lorenzi VC, Lee HJ, Falcone DJ, Hudis CA, Dannenberg AJ, et al. Exocytosis of macrophage lysosomes leads to digestion of apoptotic adipocytes and foam cell formation. J Lipid Res. 2016;57:980-92.

55. Kruth HS. Receptor-independent fluid-phase pinocytosis mechanisms for induction of foam cell formation with native low-density lipoprotein particles. Curr Opin Lipidol. 2011;22:386-93.

56. Tremblay M-Ë, Zhang I, Bisht K, Savage JC, Lecours C, Parent M, et al. Remodeling of lipid bodies bydocosahexaenoic acid in activatedmicroglial cells. J Neuroinflammation. 2016;13:1-18.

57. Iulita MF, Vallerand D, Beauvillier M, Haupert N, A Ulysse C, Gagné A, et al. Differential effect of angiotensin II and blood pressure on hippocampal inflammation in mice. J Neuroinflammation. 2018;15:62.

58. Acharjee S, Verbeek M, Gomez CD, Bisht K, Lee B, Benoit L, et al. Reduced microglial activity and enhanced glutamate transmission in the basolateral amygdala in early CNS autoimmunity. J Neurosci. 2018;38:9019-33.
59. Milior G, Lecours C, Samson L, Bisht K, Poggini S, Pagani F, et al. Fractalkine receptor deficiency impairs microglial and neuronal responsiveness to chronic stress. Brain Behav Immun. 2016;55:114-25.

60. Hui C-W, St-Pierre M-K, Detuncq J, Aumailley L, Dubois M-J, Couture $V$, et al. Brain, behavior, and immunity. Brain Behav Immun Elsevier. 2018;73:450-69.

61. Nimmerjahn A, Kirchhoff F, Helmchen F. Resting microglial cells are highly dynamic surveillants of brain parenchyma in vivo. Science. 2005;308:1314-8.

62. Solé-Domènech $\mathrm{S}, \mathrm{Cruz} \mathrm{DL}$, Capetillo-Zarate $\mathrm{E}$, Maxfield FR. Ageing research reviews Ageing Research Reviews. Elsevier B.V; 2016;32:89-103.

63. Sasaki S. Endoplasmic reticulum stress in motor neurons of the spinal cord in sporadic amyotrophic lateral sclerosis. J Neuropathol Exp Neurol. 2010;69:346-55.

64. Li J-Q, Yu J-T, Jiang T, Tan L. Endoplasmic reticulum dysfunction in Alzheimer's disease. Mol Neurobiol. 2015:51:383-95.

65. Sanchez-Varo R, Trujillo-Estrada L, Sanchez-Mejias E, Torres M, BagliettoVargas D, Moreno-Gonzalez I, et al. Abnormal accumulation of autophagic vesicles correlates with axonal and synaptic pathology in young Alzheimer's mice hippocampus. Acta Neuropathol. 2012;123:53-70.

66. Nixon RA, Wegiel J, Kumar A, Yu WH, Peterhoff C, Cataldo A, et al. Extensive involvement of autophagy in Alzheimer disease: an immuno-electron microscopy study. J Neuropathol Exp Neurol. 2005;64:113-22.

67. Nixon RA. Autophagy, amyloidogenesis and Alzheimer disease. J Cell Sci. 2007;120:4081-91.

68. Nixon RA, Yang D-S. Autophagy failure in Alzheimer's disease-locating the primary defect. Neurobiol Dis. 2011;43:38-45.

69. Ransohoff RM, Khoury El J. Microglia in health and disease. Cold Spring Harb Perspect Biol. 2015;8:a020560.

70. Meyer-Luehmann M, Spires-Jones TL, Prada C, Garcia-Alloza M, de Calignon A, Rozkalne A, et al. Rapid appearance and local toxicity of amyloid-beta plaques in a mouse model of Alzheimer's disease. Nature. 2008;451:720-4.

71. Koenigsknecht-Talboo J, Meyer-Luehmann M, Parsadanian M, Garcia-Alloza M, Finn MB, Hyman BT, et al. Rapid microglial response around amyloid pathology after systemic anti-Abeta antibody administration in PDAPP mice. J Neurosci. 2008;28:14156-64.

72. Krabbe G, Halle A, Matyash V, Rinnenthal JL, Eom GD, Bernhardt U, et al. Functional impairment of microglia coincides with Beta-amyloid deposition in mice with Alzheimer-like pathology. PLoS One. 2013;8:e60921.

73. Nestor PJ, Fryer TD, Hodges JR. Declarative memory impairments in Alzheimer's disease and semantic dementia. Neuroimage. 2006;30:1010-20.

74. Sperling RA, Aisen PS, Beckett LA, Bennett DA, Craft S, Fagan AM, et al. Toward defining the preclinical stages of Alzheimer's disease: recommendations from the National Institute on Aging-Alzheimer's Association workgroups on diagnostic guidelines for Alzheimer's disease. Alzheimers Dement. 2011;7:280-92.

75. Putcha D, Brickhouse M, O'Keefe K, Sullivan C, Rentz D, Marshall G, et al. Hippocampal hyperactivation associated with cortical thinning in Alzheimer's disease signature regions in non-demented elderly adults. J Neurosci. 2011;31:17680-8.

76. Fan Z, Okello AA, Brooks DJ, Edison P. Longitudinal influence of microglial activation and amyloid on neuronal function in Alzheimer's disease. Brain. 2015;138:3685-98.

77. Esparza TJ, Gangolli M, Cairns NJ, Brody DL. Soluble amyloid-beta buffering by plaques in Alzheimer disease dementia versus high-pathology controls. PLoS One. 2018;13:e0200251.

78. Nuntagij P, Oddo S, LaFerla FM, Kotchabhakdi N, Ottersen OP, Torp R. Amyloid deposits show complexity and Intimate spatial relationship with dendrosomatic plasma membranes: an electron microscopic 3D reconstruction analysis in 3xTg-AD mice and aged canines. JAD. 2009:16:315-23.

79. Paresce DM, Chung H, Maxfield FR. Slow degradation of aggregates of the Alzheimer's disease amyloid beta-protein by microglial cells. J Biol Chem. 1997:272:29390-7.

80. Koenigsknecht J, Landreth G. Microglial phagocytosis of fibrillar betaamyloid through a beta1 integrin-dependent mechanism. J Neurosci. 2004;24:9838-46.

81. Boissonneault V, Filali M, Lessard M, Relton J, Wong G, Rivest S. Powerful beneficial effects of macrophage colony-stimulating factor on beta-amyloid deposition and cognitive impairment in Alzheimer's disease. Brain. 2009;132:1078-92. 
82. Majumdar A, Capetillo-Zarate E, Cruz D, Gouras GK, Maxfield FR. Degradation of Alzheimer's amyloid fibrils by microglia requires delivery of CIC-7 to lysosomes. Mol Biol Cell. 2011;22:1664-76.

83. Frackowiak J, Wisniewski HM, Wegiel J, Merz GS, labal K, Wang KC Ultrastructure of the microglia that phagocytose amyloid and the microglia that produce beta-amyloid fibrils. Acta Neuropathol. 1992;84:225-33.

84. Fairn GD, Grinstein S. How nascent phagosomes mature to become phagolysosomes. Trends Immunol. 2012;33:397-405.

85. Majumdar A, Cruz D, Asamoah N, Buxbaum A, Sohar I, Lobel P, et al. Activation of microglia acidifies lysosomes and leads to degradation of Alzheimer amyloid fibrils. Mol Biol Cell. 2007:18:1490-6.

86. Stalder M, Deller T, Staufenbiel M, Jucker M. 3D-reconstruction of microglia and amyloid in APP23 transgenic mice: no evidence of intracellular amyloid. Neurobiol Aging. 2001;22:427-34.

87. Brown GC, Neher JJ. Microglial phagocytosis of live neurons. Nat Rev Neurosci. 2014;15:209-16.

88. Weinhard L, di Bartolomei G, Bolasco G, Machado P, Schieber NL, Neniskyte $\mathrm{U}$, et al. Microglia remodel synapses by presynaptic trogocytosis and spine head filopodia induction. Nat Commun. 2018;9:1228.

89. Paolicelli RC, Jawaid A, Henstridge CM, Valeri A, Merlini M, Robinson JL, et al. TDP-43 depletion in microglia promotes amyloid clearance but also induces synapse loss. Neuron. 2017:95:297-308 e6.

90. Friedman BA, Srinivasan K, Ayalon G, Meilandt WJ, Lin H, Huntley MA, et al. Diverse brain myeloid expression profiles reveal distinct microglial activation states and aspects of Alzheimer's disease not evident in mouse models. Cell Rep. 2018:22:832-47.

91. Sasaguri H, Nilsson P, Hashimoto S, Nagata K, Saito T, De Strooper B, et al. APP mouse models for Alzheimer's disease preclinical studies. EMBO J. 2017;36:2473-87.

Ready to submit your research? Choose BMC and benefit from:

- fast, convenient online submission

- thorough peer review by experienced researchers in your field

- rapid publication on acceptance

- support for research data, including large and complex data types

- gold Open Access which fosters wider collaboration and increased citations

- maximum visibility for your research: over $100 \mathrm{M}$ website views per year

At $\mathrm{BMC}$, research is always in progress.

Learn more biomedcentral.com/submissions 